\title{
Cystic fibrosis-related diabetes is caused by islet loss and inflammation
}

\author{
Nathaniel J. Hart, ${ }^{1}$ Radhika Aramandla, ${ }^{1}$ Gregory Poffenberger, ${ }^{1}$ Cody Fayolle, ${ }^{1}$ Ariel H. Thames, ${ }^{1}$ \\ Austin Bautista, ${ }^{2}$ Aliya F. Spigelman, ${ }^{2}$ Jenny Aurielle B. Babon, ${ }^{3}$ Megan E. DeNicola, ${ }^{3}$ \\ Prasanna K. Dadi, ${ }^{4}$ William S. Bush, ${ }^{5}$ Appakalai N. Balamurugan, ${ }^{6}$ Marcela Brissova, ${ }^{1}$ Chunhua Dai, \\ Nripesh Prasad, ${ }^{7}$ Rita Bottino, ${ }^{8}$ David A. Jacobson, ${ }^{4}$ Mitchell L. Drumm, ${ }^{9}$ Sally C. Kent, ${ }^{3}$ \\ Patrick E. MacDonald, ${ }^{2}$ and Alvin C. Powers ${ }^{1,4,10}$ \\ 'Department of Medicine, Division of Diabetes, Endocrinology, and Metabolism, Vanderbilt University Medical Center, \\ Nashville, Tennessee, USA. ${ }^{2}$ Department of Pharmacology and Alberta Diabetes Institute, University of Alberta, \\ Edmonton, Alberta, Canada. ${ }^{3}$ Department of Medicine, Division of Diabetes, Diabetes Center of Excellence, University of \\ Massachusetts Medical School, Worcester, Massachusetts, USA. ${ }^{4}$ School of Medicine, Department of Molecular Physiology \\ and Biophysics, Vanderbilt University, Nashville, Tennessee, USA. ${ }^{5}$ Department of Population and Quantitative Health \\ Sciences, Case Western Reserve University, Cleveland, Ohio, USA. ${ }^{6}$ Center for Cellular Transplantation, Department of \\ Surgery, Cardiovascular Innovation Institute, University of Louisville, Louisville, Kentucky, USA. ${ }^{7 H u d s o n}$ Alpha Institute of \\ Biotechnology, Huntsville, Alabama, USA. ${ }^{8}$ Allegheny Singer Research Institute, Pittsburgh, Pennsylvania, USA. \\ ${ }^{9}$ School of Medicine, Department of Genetics, Case Western Reserve University, Cleveland, Ohio, USA \\ ${ }^{10}$ VA Tennessee Valley Healthcare, Nashville, Tennessee, USA.
}

Cystic fibrosis-related (CF-related) diabetes (CFRD) is an increasingly common and devastating comorbidity of CF, affecting approximately $35 \%$ of adults with CF. However, the underlying causes of CFRD are unclear. Here, we examined cystic fibrosis transmembrane conductance regulator (CFTR) islet expression and whether the CFTR participates in islet endocrine cell function using murine models of $\beta$ cell CFTR deletion and normal and CF human pancreas and islets. Specific deletion of CFTR from murine $\beta$ cells did not affect $\beta$ cell function. In human islets, CFTR mRNA was minimally expressed, and CFTR protein and electrical activity were not detected. Isolated CF/ CFRD islets demonstrated appropriate insulin and glucagon secretion, with few changes in key islet-regulatory transcripts. Furthermore, approximately $65 \%$ of $\beta$ cell area was lost in CF donors, compounded by pancreatic remodeling and immune infiltration of the islet. These results indicate that CFRD is caused by $\beta$ cell loss and intraislet inflammation in the setting of a complex pleiotropic disease and not by intrinsic islet dysfunction from CFTR mutation.

Conflict of interest: The authors have declared that no conflict of interest exists.

Submitted: November 27, 2017

Accepted: March 14, 2018

Published: April १९, 2018

Reference information: JCI Insight. 2018;3(8):e98240. https://doi.org/10.1172/jci. insight. 98240.

\section{Introduction}

Cystic fibrosis (CF) is a monogenic autosomal disease caused by mutations in the cystic fibrosis transmembrane conductance regulator (CFTR). Loss of CFTR protein function disrupts bicarbonate, salt, and fluid flux across epithelial-lined tissues and impairs the physiology of numerous organs. As greater numbers of individuals with CF live longer, the prevalence of CF-related diabetes (CFRD) has increased dramatically, affecting approximately $35 \%$ of adults with CF (1). Importantly, CFRD exacerbates CF-related complications and is associated with increased mortality $(2,3)$. CFRD is recognized as a form of type $3 c$ (pancreatogenic) diabetes but is often regarded as a distinct clinical entity $(2,4)$, as CFRD displays features of both type 1 diabetes (T1D) and type 2 diabetes (T2D) that occur in the setting of pancreatic insufficiency, multiorgan dysfunction, chronic infection, malabsorption, malnutrition, and varying degrees of insulin resistance (5-10).

Recently, loss of CFTR function in cell lines and cultured rodent/ferret and human islets has been reported to impair insulin secretion (11-14) and augment glucagon secretion $(15,16)$, suggesting that loss of CFTR function in islet endocrine cells contributes to CFRD via intrinsic disruption of $\beta$ and $\alpha$ cell stimulus-secretion coupling. Conversely, studies of humans and CF animal models have suggested that CFRD results from $C F$-induced pancreatic autolysis, inflammation, and reduction of $\beta$ cell mass (17-20) causing insufficient islet hormone secretion (20-27). These findings are supported by an association among CFRD, 
A

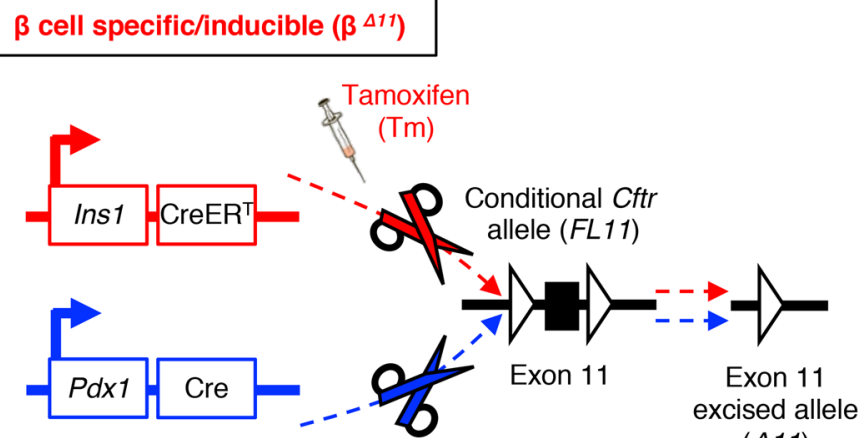

$(\Delta 11)$
B

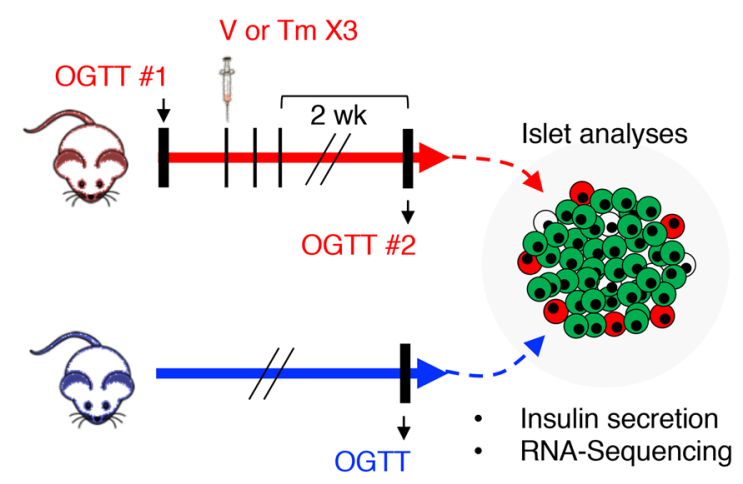

Pancreatic/constitutive (Panc ${ }^{411}$ )

C
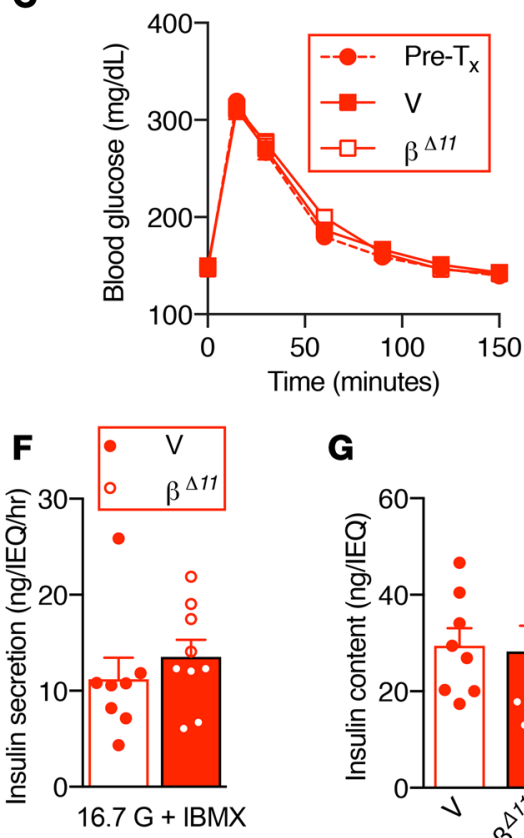

D

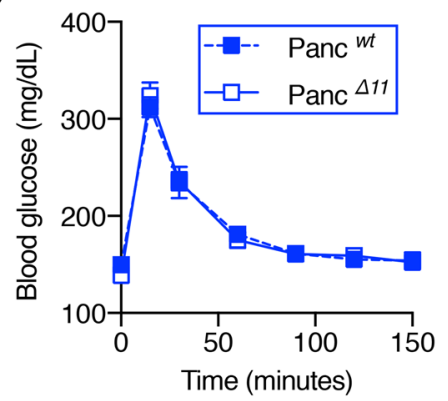

H

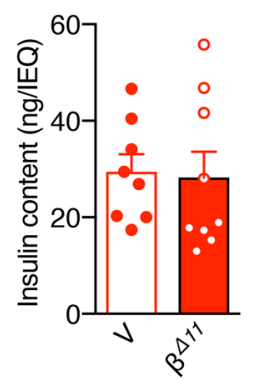

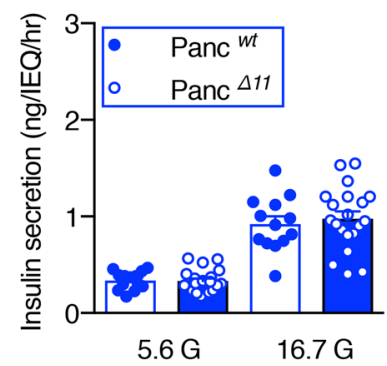

E

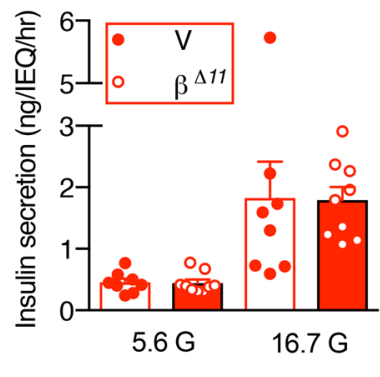

I

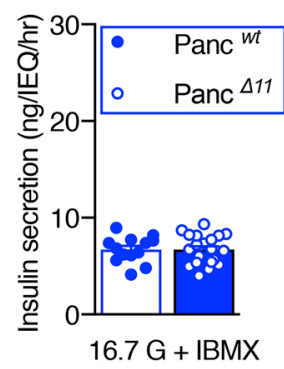

J

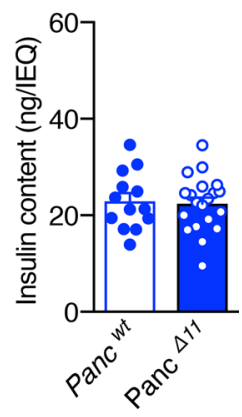

Figure 1. $\beta$ Cell CFTR deletion did not alter murine oral glucose tolerance or islet insulin secretion. (A) Murine models created to excise $C f t r$ exon 11 from $\beta$ cells in an inducible fashion ( $\beta^{\Delta 11}$ ) or from the pancreas with constitutive Cre action (Panc ${ }^{\Delta 11}$ ). (B) Experimental timeline of murine models. Analyses included oral glucose tolerance testing (OCTT) on conscious animals, insulin secretion assays, and RNA sequencing of whole islets. OGTT of (C) male $\beta$ cell-specific/ inducible mice prior to (Pre- $\left.\mathrm{T}_{\mathrm{x}} ; n=46\right)$ and after treatment with vehicle $(\mathrm{V} ; n=17)$ or tamoxifen $\left(\beta^{411} ; n=23\right)$ and (D) pancreatic/constitutive mice homozygous for the $C f t r^{\text {wt }}$ allele (Panc ${ }^{\text {wt }} ; n=8$ ) and mice homozygous for the $C f t r r^{F L 11}$ allele (Panc ${ }^{411} ; n=11$ ). Insulin secretion from isolated islets incubated in medium containing (E and $\mathbf{H}) 5.6 \mathrm{mM}$ glucose (5.6 G), $16.7 \mathrm{mM}$ glucose (16.7 G), or (F and I) $16.7 \mathrm{mM}$ glucose and $100 \mu \mathrm{M}$ 3-isobutyl-1-methylxanthine (16.7 G + IBMX), and ( $\mathbf{G}$ and $\mathbf{J}$ ) islet insulin content from $\beta$ cell-specific/inducible mice (E-G: V, $n=8,5$ male, 3 female; $\beta^{411}, n=9,6$ male, 3 female) and pancreatic/constitutive mice (H-J: Panc ${ }^{\mathrm{wt}}, n=13,6$ male, 7 female; Panc ${ }^{411}, n=20,10$ male, 10 female). We observed slight differences in glucose-stimulated insulin secretion, cAMP-potentiated GSIS, and islet insulin content between the control animals of the $\beta^{\Delta 11}$ and Panc ${ }^{\Delta 11}$ models. However, the control animals were individualized for each model and differ in the type of Cre recombinase expressed as well as the expression promotor (A). Red represents the $\beta$ cell-specific/inducible model ( $\beta{ }^{411}$ ), blue the pancreatic constitutive model (Panc $\left.{ }^{411}\right)$. Data represent mean \pm SEM. No statistical significance $(P<0.05)$ was observed in OGTT AUC, insulin secretion, or insulin content in either model. Statistical data were calculated with 1-way ANOVA (C and $\mathbf{D}$ ) or unpaired 2-tailed Student's $t$ test (E-J).

exocrine disease severity, and pancreatic insufficiency $(3,28)$. Thus, the relative contributions of intrinsic islet cell dysfunction and islet loss to the pathogenesis of CFRD remain unclear.

To elucidate the underlying causes of CFRD and the role of CFTR in islet cell function, we generated acute and chronic models of $\beta$ cell-specific CFTR deletion and investigated the effect(s) of CFTR loss on glucose tolerance and/or $\beta$ cell function. As human islets possess a number of unique and important differences relative to rodent islets (29-34) and knowledge regarding CFTR expression and function in human 
islets is limited $(11,15,35)$, we examined CFTR mRNA and protein expression in human islet endocrine cells, whether CFTR regulates human islet insulin secretion, and the hormone secretory profile and transcriptome of human CF islets. Our studies indicate that the CFTR does not intrinsically regulate $\alpha$ or $\beta$ cell function and that the etiology of CFRD is largely dependent on islet loss and intraislet inflammation in the setting of a complex and progressive multiorgan disease.

\section{Results}

Deletion of $\beta$ cell CFTR did not affect glucose tolerance. To directly test whether CFTR intrinsically regulates $\beta$ cell insulin secretion, we created two murine models of $\beta$ cell CFTR deletion (Figure 1A) and assessed glucose tolerance, islet insulin secretion, and islet gene expression (Figure 1B). A $\beta$ cell-specific/inducible CFTR-knockout $\left(\beta^{\Delta 11}\right)$ mouse model allowed us to investigate the effects of acute $\beta$ cell CFTR deletion in adult mice. We also generated a pancreatic/constitutive CFTR-knockout (Panc ${ }^{411}$ ) mouse to investigate the effect of CFTR deletion in pancreatic cells during development and persistent deletion in adult $\beta$ cells. Importantly, we have shown that excision of Cftr exon 11 renders the CFTR electrically silent (36). Oral glucose tolerance testing (OGTT) to assess whole-animal glucose handling was similar to controls in both $\beta^{\Delta 11}$ (Figure 1C; Supplemental Figure 1, B-F; and Supplemental Figure 2, A-F; supplemental material available online with this article; https://doi.org/10.1172/jci.insight.98240DS1) and Panc ${ }^{411}$ (Figure 1D and Supplemental Figure 1, H-L) male and female animals. These results indicate that deletion of CFTR from murine $\beta$ cells did not affect glucose homeostasis.

Insulin secretion was not affected by CFTR $\beta$ cell deletion. To investigate whether $\beta$ cell CFTR deletion caused an insulin secretory defect that was not detected by OGTT, we isolated islets and measured insulin secretion. Basal insulin secretion, glucose-stimulated insulin secretion (GSIS), cAMP-potentiated GSIS (pGSIS), and islet insulin content were similar to those of control islets in both the $\beta^{\Delta 11}$ and Panc ${ }^{\Delta 11}$ models (Figure 1, E-J, and Supplemental Figure 2, H-J). We also perifused islets from Panc ${ }^{\Delta 11}$ animals and found that GSIS and pGSIS were similar between control and Panc ${ }^{411}$ islets (Supplemental Figure 1, M and N).

To address whether $\mathrm{Ca}^{2+}$ handling was impaired in murine $\beta$ cells with loss of CFTR function, as previously reported (12), we assessed $\mathrm{Ca}^{2+}$ handling in single $\beta$ cells isolated from $\beta{ }^{\Delta 11}$ animals. We found that glucose-stimulated $\mathrm{Ca}^{2+}$ handling in single $\beta$ cells was similar to that of control $\beta$ cells (Supplemental Figure 1 , $\mathrm{O}-\mathrm{R})$. These results suggest that CFTR did not intrinsically regulate murine $\beta$ cell insulin secretion or content.

Key islet regulatory gene expression was not affected by CFTR deletion. Given the $\beta$ cell dysfunction and disturbed ion flux reported by others in a CF murine model (12) and the ability of $\beta$ cell dysfunction to affect the islet transcriptome (37), we performed RNA sequencing on whole islets from both murine models. Evaluation of selected islet-enriched transcripts revealed few differences in expression over 2-fold change between control and experimental animals of either model (Supplemental Figure 1, S and T).

Human islet endocrine cells showed minimal CFTR $m R N A$ expression that did not result in detectable CFTR protein. To determine whether CFTR has a role in insulin secretion in human $\beta$ cells, we investigated CFTR expression and function in human islet endocrine cells. We first searched 3 previously published gene expression data sets of FACS-sorted $\beta$ and $\alpha$ cells based on intracellular or extracellular labeling methods and single-cell sequencing of endocrine and exocrine cell types for CFTR and comparator transcripts (38-40). RNA sequencing of 270 single $\beta$ cells isolated from nondiabetic and diabetic individuals by Segerstolpe et al. (38) (Figure 2A and Supplemental Figure 3A) and of sorted $\beta$ cells by Blodgett et al. (39) (Figure 2B and Supplemental Figure 4A) and Bramswig et al. (40) (Supplemental Figure 4C) revealed that CFTR transcript was minimally expressed in $\beta$ cells. Of 270 single cells in the Segerstolpe et al. (38) data set, approximately $5 \%$ of $\beta$ cells displayed $C F T R$ reads per kilobase of transcript per million mapped reads (RPKM) values $>1$, with a maximum $C F T R$ expression value of 4.2 RPKM (Supplemental Figure 3E). For comparison, GLRA1, a chloride channel that we have previously shown to effect $\beta$ cell stimulus-secretion coupling (41), was expressed at RPKM values $>1$ in approximately $40 \%$ of $\beta$ cells, with a maximum expression value of 123.2 RPKM. CFTR expression, when detected, was also several fold less than islet-enriched transcription factors important in $\beta$ cell identity maintenance and insulin secretion (Figure $2, \mathrm{~A}$ and $\mathrm{B}$ ).

Minimal CFTR expression in the aforementioned data set (38) was also found in other islet endocrine cells. Approximately $3 \%$ of $874 \alpha$ cells expressed CFTR transcript at RPKM values $>1$, with a maximum expression of 5.6 RPKM (Supplemental Figure 3, B and F), and approximately 4\% of the $114 \delta$ cells expressed CFTR with RPKM values $>1$, with a maximum expression of 14.9 RPKM (Supplemental Figure 3, C and G). Single exocrine cells, as we expected, expressed relatively high levels of CFTR and other 
A

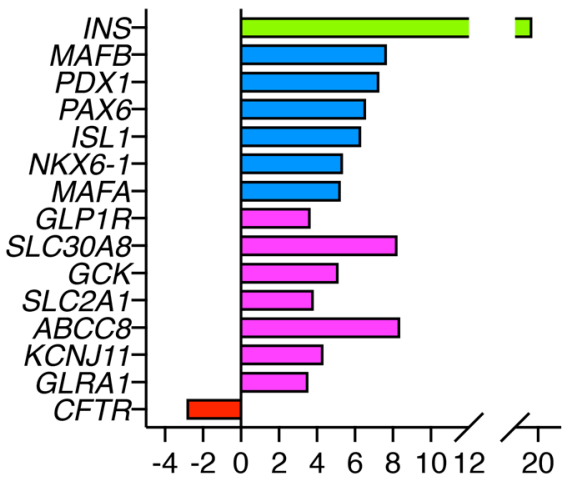

$\log _{2}(\beta$ cell mean expression RPKM)

B

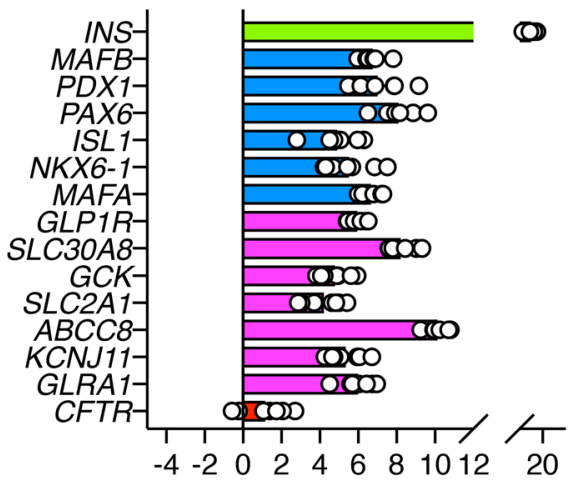

$\log _{2}(\beta$ cell expression TPM)
C
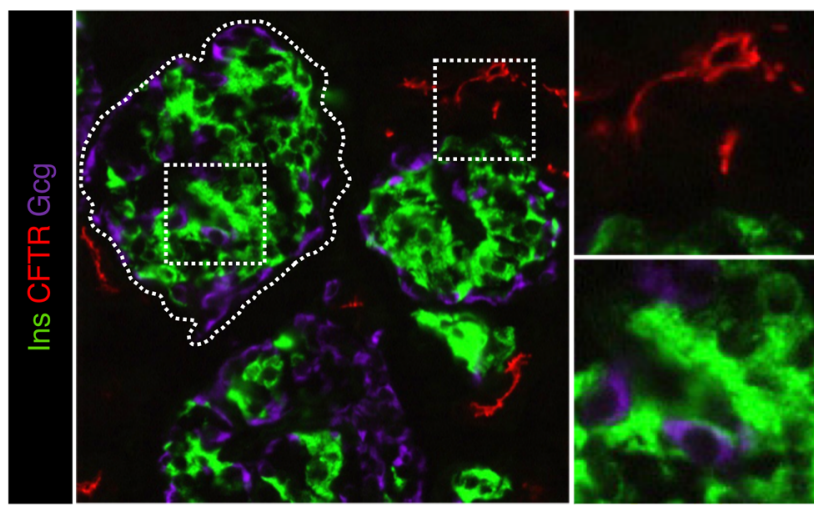

D
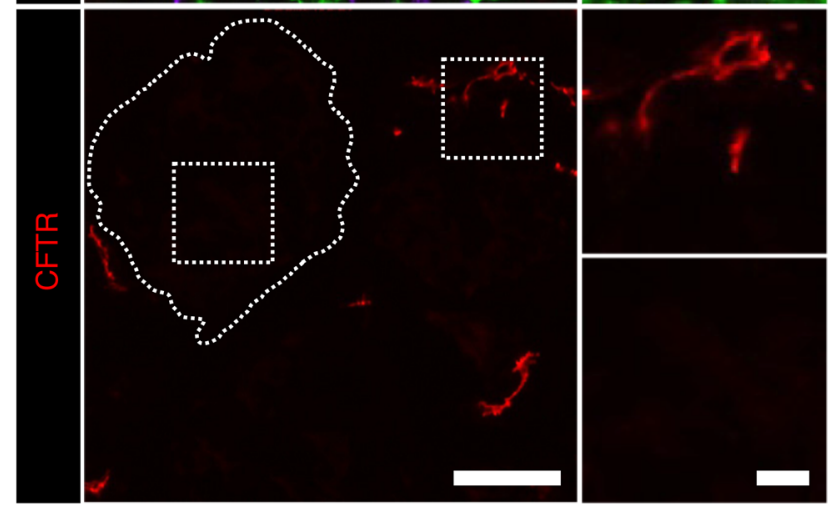

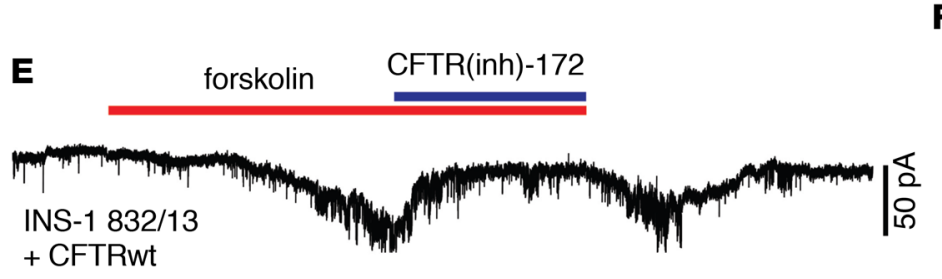

F

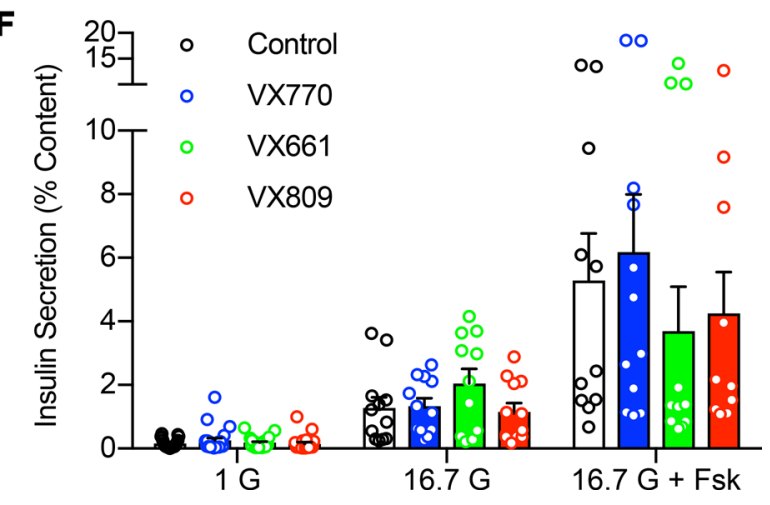

Figure 2. CFTR mRNA expression was minimal in human $\boldsymbol{\beta}$ cells, and CFTR protein was undetectable in human $\boldsymbol{\beta}$ cells. Expression of CFTR and select $\beta$ cell-related transcripts from published islet cell transcriptomes: (A) 270 single human $\beta$ cells from 6 healthy and 4 diabetic donors (reads per kilobase of transcript per million mapped reads [RPKM], Segerstolpe and Palasantza et al., ref. 38) and (B) sorted $\beta$ cells from 7 healthy adult donors (transcript per kilobase million [TPM], Blodgett et al., refs. 39). Note: Individual expression values are not presented in $\mathbf{A}$, as the log ${ }_{2}$ of the mean expression value of $270 \beta$ cells was calculated to account for the approximately $85 \%$ of $\beta$ cells in this data set that do not express CFTR; individual CFTR expression values are presented in Supplemental Figure 3E. Green bar, insulin; blue bars, key islet transcription factors; pink, islet hormone secretion related genes; red, CFTR. (C) Representative immunohistochemical labeling of CFTR (red), insulin (green), and glucagon (purple) in a pancreas from 3-month-old male donor. Insets depict the islet border and interior. (D) CFTR (red) channel alone (note: CFTR ductal localization and islet absence). Scale bars: $50 \mu \mathrm{m}$ (C and $\mathbf{D}) ; 10 \mu \mathrm{m}$ (insets). (E) Representative patch clamp recording of a human $\beta$ cell and a INS832/13 + wtCFTR cell ( $n=5$ donors, $35 \beta$ cells; Supplemental Figure 5B). (F) Insulin secretion from human islets ( $n=4$ donors) in medium containing $1 \mathrm{mM}$ glucose (1 G), $16.7 \mathrm{mM}$ glucose (16.7 G), or 16.7 G plus $100 \mu \mathrm{M}$ forskolin (16.7 G + Fsk) and no drug (white), $1 \mu \mathrm{M}$ VX770 (blue, ivacaftor), $5 \mu \mathrm{M}$ VX661 (green), or $5 \mu \mathrm{M}$ VX809 (red, lumacaftor). 1 G, $n=22-24$ replicates; 16.7 G, $n=11-12$ replicates; $16.7+$ Fsk, $n=10-12$ replicates. VX770 is a selective CFTR potentiator that increases CFTR activity at the membrane and VX661, and VX809 are CFTR channel correctors that increase membrane channel density. Data represent mean \pm SEM. No statistical significance $(P<0.05)$ was observed in in vitro human islet insulin secretion when comparing secretory responses at $1 \mathrm{G}, 16.7 \mathrm{G}$, and 16.7 G + Fsk in the presence of absence of CFTR modulators. One-way ANOVA was used for statistical analysis. 
markers of exocrine tissue (Supplemental Figure 3, D and H). Thus, 3 independent human islet cell gene expression data sets found minimal expression of the CFTR transcript.

We also investigated CFTR protein expression and location in the human pancreas. Since suitable antibodies for detection of CFTR protein have been problematic (42), we sought to identify a specific antibody for detection of CFTR protein by screening the specificity of 3 anti-CFTR monoclonal antibodies (antibodies 217, 432, 450) from the Cystic Fibrosis Foundation (CFF) against HeLa cells (which did not express CFTR), HeLa CFTR cells (which expressed human CFTR), and the Calu-3 line (which endogenously expressed CFTR). Using immunocytochemistry, we found that antibody 217 nonspecifically labeled all cells and antibodies 432 and 450 specifically labeled CFTR protein. However, we observed some nonspecific labeling of antibody 450 on HeLa cells and determined that antibody 432 was most suited for detecting human CFTR protein (Supplemental Figure 5A). Using this validated antibody, we labeled human pancreatic sections from 4 normal human donors over a range of ages ( 1 day to 4 years) and found that CFTR protein was localized to the ducts of the pancreas but was not present in insulin-positive, glucagon-positive (Figure 2, C and D, and Supplemental Figure 3, C-H), or somatostatin-positive (Supplemental Figure 5, I-P) cells. This staining pattern was also observed in human pancreata studied by The Human Protein Atlas (43). These data indicate that CFTR protein was not detectable in human islet endocrine cells by immunochemistry.

To determine if functional CFTR protein was present in human $\beta$ cells, we recorded forskolin-activated and chloride currents sensitive to the channel inhibitor CFTR(inh)-172 in human $\beta$ cells but did not detect CFTR(inh)-172-sensitive chloride currents (Figure 2E and Supplemental Figure 5B). To further assess whether functional CFTR protein was present in human $\beta$ cells, we incubated human islets with 3 specific modulators of CFTR function, VX770 (ivacaftor), a CFTR potentiator, and VX661 (tezacaftor) and VX809 (lumacaftor), both CFTR correctors, and measured insulin secretion in response to nonstimulatory and stimulatory conditions. Insulin secretion in the presence of each CFTR modulator was similar to untreated islets at $1 \mathrm{mM}$ glucose, $16.7 \mathrm{mM}$ glucose, and $16.7 \mathrm{mM}$ glucose $+100 \mu \mathrm{M}$ forskolin (Figure $2 \mathrm{~F}$ ). Taken together, these data indicate that CFTR did not intrinsically control human $\beta$ cell membrane potential or insulin secretion.

Analyses of human CF pancreata and islets. To examine the effect of CF-causing mutations on insulin secretion, we established a nationwide network to obtain and study pancreas, islets and deidentified medical records from CF donors and healthy age-matched donors. To maximize the data collected from CF pancreata, we developed a protocol to obtain pancreatic tissue and isolate islets from a single CF organ. This approach allowed for integrated investigation of pancreatic tissue, CFTR mutations, islet function, islet gene expression, and immune activity (Figure 3). We obtained 7 CF pancreata from 2013-2017 from individuals with the diagnosis of CF (Table 1). All donors had pancreatic insufficiency, with numerous clinical contacts, medical procedures, and medications. All the donors but donor 1 were diagnosed with CFRD (Table 1). C-peptide measured in blood taken at the time of organ procurement in $3 \mathrm{CF}$ donors was in the normal to elevated range $(1.83-4.54 \mathrm{ng} / \mathrm{ml})$, while one donor had low C-peptide (0.04 $\mathrm{ng} / \mathrm{ml})$ (Table 1).

$C F$ distorted the pancreatic islet niche and reduced $\beta$ cell area. To examine the islet niche in the setting of $\mathrm{CF}$, we interrogated $\mathrm{CF}$ pancreatic tissue by measuring $\beta$ cell area, endocrine cell populations, amyloid deposition, $\beta$ cell proliferation, and apoptosis. The gross anatomic appearance of each CF pancreas was abnormal. CF pancreata were fatty and fibrotic in appearance (Supplemental Figure 6). CF pancreata were almost completely devoid of exocrine tissue and displayed large aggregations of islets, regions of pancreatic lipomatosis and fibrosis, cyst-like structures, and dilated duct-like structures (Figure 4, A-C), as also described by others $(10,17,18,44)$. Abnormal islet aggregation (Figure 4E), disruption of islet structure, endocrine cell scattering, and intraislet dilated duct-like structures (Figure 4F) were also observed. However, some islets appeared morphologically "normal," but all islets were present in ectopic niches, i.e., encased in adipose and/or fibrotic tissue.

Pancreatic $\beta$ cell area in CF donors was reduced approximately $65 \%$ (Figure $4 \mathrm{D}$ ), with the majority of CF $\beta$ cell area confined to large islet aggregations. We also found an increased contribution of $\alpha$ cells, but not $\beta$ or $\delta$ cells, to the endocrine compartment ( $\alpha, \beta, \delta$ cells) of the CF pancreas (Figure $4 \mathrm{G}$ ). We did not find differences in $\beta$ cell apoptosis or proliferation (Supplemental Figure 7, A and B) with the exception of increased $\beta$ cell apoptosis in donor 6 (Figure 4H). We also found intraislet amyloid in donors 1 and 5 (previous report, ref. 10) (Figure 4I). These data demonstrate that the islet niche, islet morphology, and pancreatic $\beta$ cell area were altered in CF, which likely affects in vivo hormone secretory and delivery capacity. 


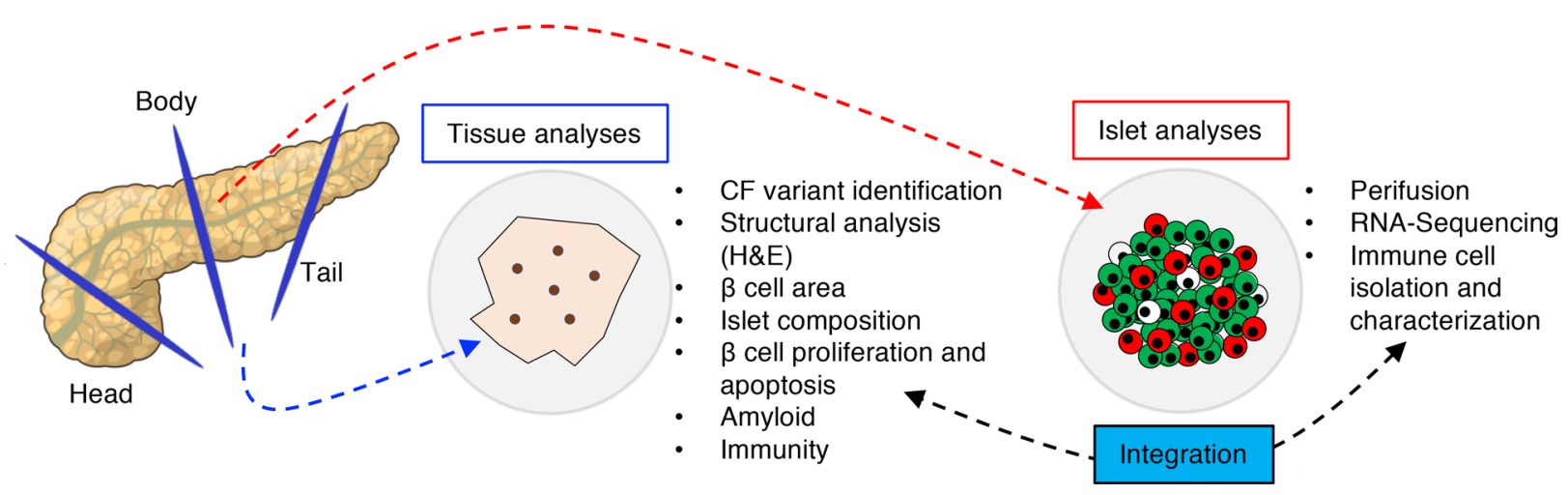

Figure 3. Pancreatic processing allowed for multidisciplinary investigation of the CF pancreas. Acquisition of intact pancreatic tissue and islets from the same pancreas allowed for integration of in situ pancreatic characteristics with in vitro islet function, the islet transcriptome, and islet immune infiltration.

Stimulated insulin and glucagon secretion and key islet regulatory genes were maintained in CF islets. To determine the secretory profile CF islets, we simultaneously measured in vitro CF islet insulin and glucagon secretion by perifusion. Following normalization of islet secretion to islet equivalents (IEQs), total hormone content, and conditions of maximal stimulation, 5 of 5 CF donors displayed phasic GSIS, pGSIS, hypoglycemic epinephrine inhibition of insulin secretion, and $\mathrm{KCl}$-mediated insulin secretion (Supplemental Figure 8, A-E). CF islet insulin secretory profiles (normalized to IEQ and insulin content) displayed insulin secretory responses above, within, or below the range of normal islets (Figure 5, A and C, and Supplemental Figure 9). There was a statistical difference between CF and normal islet insulin secretory values (normalized to IEQ or percentage content) when all values $(n=5$ donors/group $\times 50$ values $/$ perifusion $=250$ insulin secretory values) were compared (IEQ: $P=0.0021$; percentage content: $P<0.0001)$. To further investigate possible differences in CF and normal islets, we performed additional statistical analyses and found that insulin secretion was not equal between $\mathrm{CF}$ and normal islets at all time points $(P<0.0001)$; there was only one significantly different time point in the IEQ normalization $(t=126$ minutes, during perifusion with $5.6 \mathrm{G}+\mathrm{KCl}$ ) and there were no significantly different time points in the percentage content normalization, using Sidak's multiple comparison test. However, when aggregating insulin secretory values across all time points, there were no significant differences between $\mathrm{CF}$ and normal insulin secretory responses (IEQ: $P=0.8231$; percentage content: $P>0.999$ ). Importantly, these analyses indicate that the mean CF insulin secretory response to a number of conditions was similar to that of normal islets, regardless of normalization (Figure 5, B and D, and Supplemental Figure 9). To further investigate islet insulin secretion, we calculated the insulin secretion AUC and found no significant differences in insulin secretion AUC between CF and normal donors (Supplemental Figure 10). Additionally, the CF islet insulin content and stimulation index were similar to those of normal islets (Figure 5, E and F). CF islet glucagon secretion was similar to that of control islets; however, we observed elevated glucagon secretion in some donors when secretion was normalized to glucagon content and $1.7 \mathrm{mM}$ glucose plus $1 \mu \mathrm{m}$ epinephrine (Supplemental Figures 11 and 12). Taken together, these data suggest that CF $\beta$ cell insulin secretion, in particular GSIS and pGSIS, and glucagon secretion were similar to those of control islets.

To examine gene expression in CF islets, we performed whole-islet RNA sequencing on islets from 5 $\mathrm{CF}$ donors and examined transcripts important in islet cell identity, maintenance, and hormone secretion. $\mathrm{CF}$ islets had few gene expression changes over 2-fold, compared with healthy islets, in selected islet-enriched transcripts, with the exception of $A R X$ (Figure 5G).

$C F$ pancreata and islets were infiltrated by immune cells. Given the extent of remodeling of the CF pancreas, we hypothesized that the CF pancreas and islets would be infiltrated by immune cells, a process reported to contribute to both T1D $(45,46)$ and T2D $(47,48)$. To investigate this hypothesis, we stained pancreatic sections for the pan-immune cell marker CD45 and found a profound immune infiltration of the CF pancreas and islets (Figure 6, A and B). The infiltrate was both peri-islet and intraislet (Figure 6, A and B, insets). $\mathrm{CD} 45^{+}$cells were also observed throughout the remnant CF pancreas (Figure 6, A and B). Approximately $5 \%$ of the $\mathrm{CF}$ pancreas was composed of $\mathrm{CD} 45^{+}$cells, an approximately 5 -fold increase compared with normal pancreas (Figure 6C). RNA sequencing of whole CF islets also revealed an approximately 5-fold 
Table 1. Demographic and CF-causing variants in CF donors

\begin{tabular}{|c|c|c|c|c|c|c|c|c|}
\hline No. & Age (yr) & Sex & BMI & CFTR variant 1 & CFTR variant 2 & Variant class & Diabetes & C-peptide (ng/ml) \\
\hline $1^{A, B}$ (black) & 25 & M & 19.1 & $\begin{array}{c}\text { c.1521_1523delCTT } \\
\text { (p.Phe508del) (legacy: } \\
\Delta \text { F508) }\end{array}$ & $\begin{array}{l}\text { c.1521_1523delCTT } \\
\text { (p.Phe508del) } \\
\text { (legacy: } \Delta \text { F508) }\end{array}$ & II,II & No & 2.26 \\
\hline $3^{A, B}$ (green) & 34 & $\mathrm{~F}$ & 14.7 & $\begin{array}{l}\text { c.1521_1523delCTT } \\
\text { (p.Phe508del) } \\
\text { (legacy: } \Delta \text { F508) }\end{array}$ & $\begin{array}{c}\text { c.1521_1523delCTT } \\
\text { (p.Phe508del) (legacy: } \\
\Delta \text { F508) }\end{array}$ & II,II & Yes, 6-10 yr & 1.83 \\
\hline $4^{\mathrm{A}, \mathrm{B}}(\mathrm{red})$ & 24 & M & 24.1 & $\begin{array}{l}\text { c.1521_1523delCTT } \\
\text { (p.Phe508del) } \\
\text { (legacy: } \Delta \text { F508) }\end{array}$ & $\begin{array}{c}\text { c.1521_1523delCTT } \\
\text { (p.Phe508del) (legacy: } \\
\Delta \text { F508) }\end{array}$ & II,II & Yes, $>10$ yrs & 0.04 \\
\hline $5^{A}$ (teal) & 34 & $\mathrm{~F}$ & 17.0 & $\begin{array}{l}\text { c.1521_1523delCTT } \\
\text { (p.Phe508del) } \\
\text { (legacy: } \Delta \text { F508) }\end{array}$ & $\begin{array}{c}\text { c.1521_1523delCTT } \\
\text { (p.Phe508del) (legacy: } \\
\Delta \text { F508) }\end{array}$ & II,II & Yes, 6-10 yr & ND \\
\hline $7^{A, B}$ (purple) & 42 & $\mathrm{~F}$ & 27.7 & $\begin{array}{c}\text { c.3909C > G } \\
\text { (p.Asn1303Lys) } \\
\text { (legacy:N1303K) }\end{array}$ & $\begin{array}{c}\text { c.1657C > T } \\
\text { (p.Arg553X) } \\
\text { (legacy:R553X) }\end{array}$ & II,I & Yes, <1 yr & ND \\
\hline
\end{tabular}

AIslet isolation; ${ }^{B}$ whole-islet RNA sequencing. All donors were of European descent. Donor color designations correlate with data presented in Figure 4 , D and C; Figure 5, A, C, and E; and Figure 6, C and D. ND, not determined. There are 5 CFTR mutation classes that cause CF. Classes I-III cause the most severe forms of CF. All donors had class I mutations, which result in no production of CFTR protein, and/or class II mutations, which disrupt protein folding and membrane localization. Legacy name refers to the mutation in the Cystic Fibrosis Mutation Data base (http://www.genet.sickkids.on.ca/app).

increase in PTPRC (also known as CD45) transcript expression (Figure 6E). We also determined the number of $\mathrm{CD}_{4} 5^{+}$cells within $20 \mu \mathrm{m}$ of islets in CF donors (Figure 6D) and discovered that the majority of $\mathrm{CF}$ donors met the numerical criterion (3 islets with $15 \mathrm{CD} 45^{+}$cells in proximity of the islet) for insulitic classification; however, CF islets did not display overt (pseudo)atrophic islets (also required for this insulitis classification) that are a hallmark of T1D (49).

To further characterize the nature of immune islet infiltration, we performed DAVID and Ingenuity pathway analysis analyses of the CF islet transcriptome. Pathway analyses demonstrated significant activation of numerous immune pathways related to immune cell homing, activation, and signaling (Supplemental Figure 13, A and B). In addition, transcripts related to innate and adaptive immune cells, immune chemotactic and signaling chemokines, inflammatory cytokines, and generalized immune signaling and homing were increased in CF islets (Figure 6E). These data demonstrate immune cell infiltration of the $\mathrm{CF}$ islet as well as a complex immune signaling environment within the $\mathrm{CF}$ islet.

To characterize the adaptive CF islet immune infiltrate, we sorted T cells from islets of one islet preparation (donor 5), using a method previously described for the islets of donors with T1D (50). We found 4 types of islet-infiltrating $\mathrm{T}$ cells: $\mathrm{CD}^{+} \mathrm{CD}^{+}$naive $\mathrm{T}$ cells, stem cell memory $\mathrm{T}$ cells, $\mathrm{CD}^{+} 5 \mathrm{RA}^{-}$ central memory and effector T cells (Supplemental Figure 14, A-H). The phenotypes and presence of these $\mathrm{T}$ cells likely indicate an ongoing islet-infiltrating immune response. Forty-two $\mathrm{T}$ cell lines were also cultured from islets of donor 5. These consisted of CD4 lines $(n=10)$, CD8 lines $(n=9)$, and lines containing both CD4 and CD8 T cells (mixed) $(n=23)$, all of which were phenotyped. A representative $\mathrm{CD}^{+} \mathrm{T}$ cell line that displayed moderate IFN- $\gamma$ and high TNF- $\alpha$ production upon stimulation is shown in Figure 6, F-H. CD4 lines generally expressed low levels of proinflammatory cytokines (IFN- $\gamma$ and TNF- $\alpha$ ) and undetectable to low levels of a degranulation marker (CD107a) (Supplemental Table 1). The CD8 lines strongly expressed proinflammatory cytokines and the degranulation marker (Supplemental Table 2). CD4 T cells within the mixed lines were moderately proinflammatory upon stimulation, while CD8 T cells within the mixed lines were strongly proinflammatory (Supplemental Table 3). These data suggest that an adaptive immune infiltration of CF islet was capable of producing inflammatory cytokines, which impair in vivo $\beta$ cell function (51). 

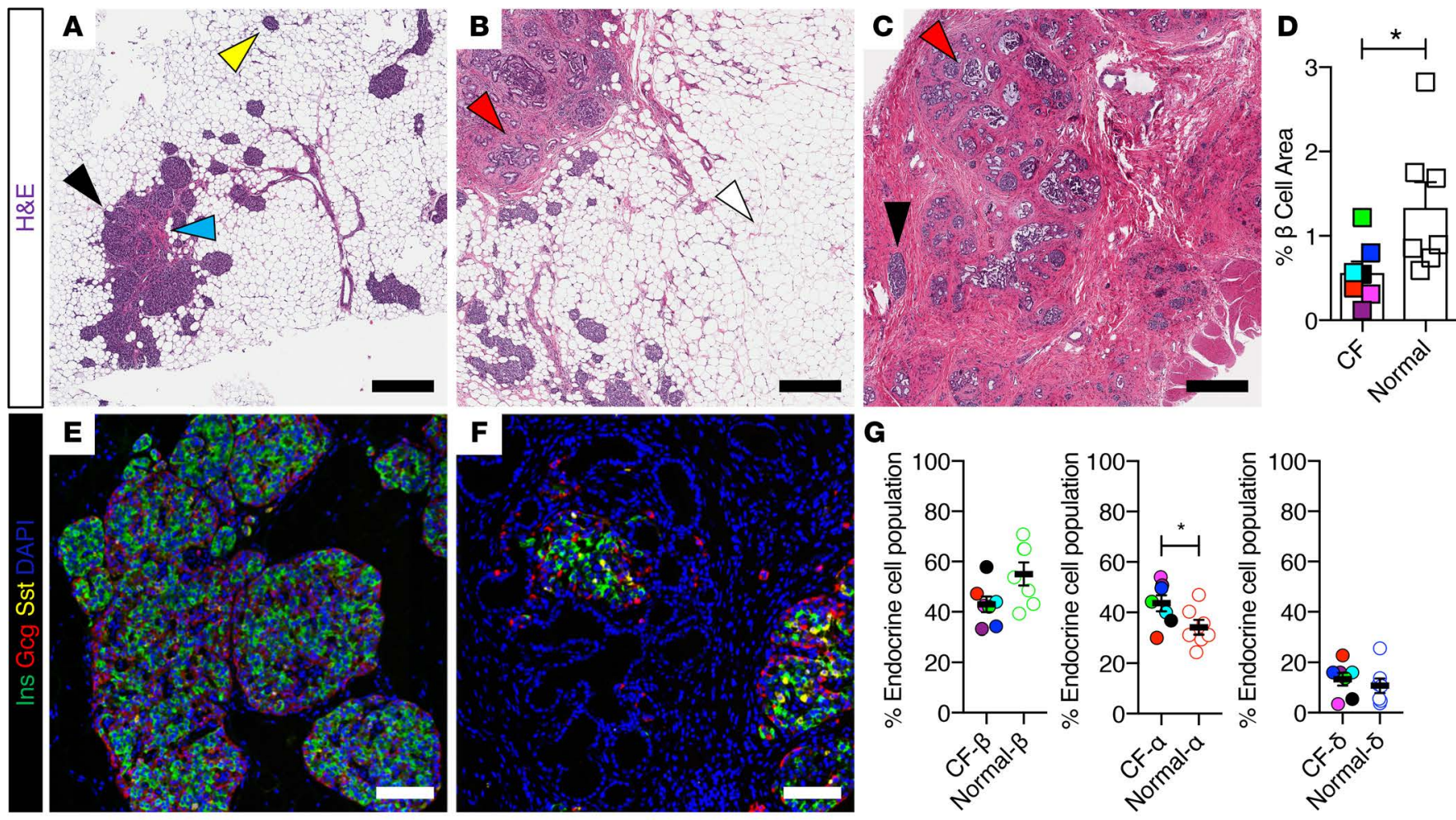

\section{G}
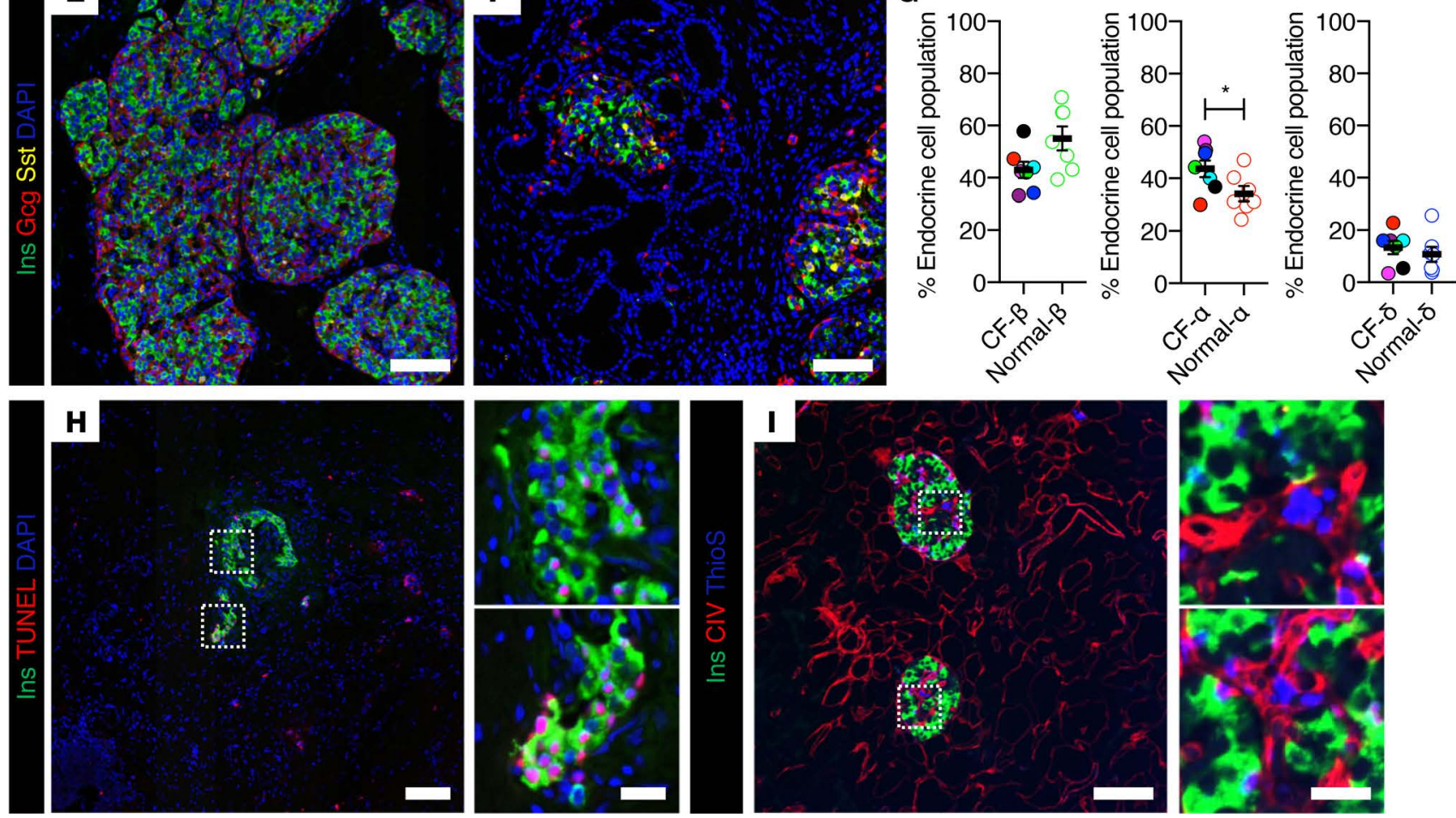

Figure 4. CF pancreata were severely remodeled, with ectopic adipose and fibrotic tissue deposition accompanied by $\beta$ cell loss. Characteristic CF-related pancreatic pathology observed in (A) donor 1: islet aggregations (black arrowhead) with inter-islet fibrosis (blue arrowhead) and islets in adipose niches (yellow arrowhead). Pathology observed in (B) donor 2: ectopic adipose (white arrowhead) and fibrotic deposition (red arrowhead). (C) Pathology observed in donor 3: formation of fibrotic cyst-like structures with embedded dilated duct-like structures (red arrowhead) and islets in fibrotic niches (black arrowhead). The pancreata from all donors lacked discernible exocrine tissue. Scale bars: $500 \mu \mathrm{m}$. (D) $\beta$ Cell area of CF donors $(n=7)$ compared with healthy pancreatic donors ( $n=7)$. Examples of abnormal islet morphology: (E, donor 1$)$ islet aggregations and (F, donor 2$)$ scattering of islet cells and dilated structures within and around islets. Scale bars: $100 \mu \mathrm{m}$. (C) Percentage of $\beta, \alpha$, and $\delta$ cells relative to all $\beta, \alpha$, and $\delta$ cells in the CF pancreas ( $n=7)$ compared with healthy donors $(n=5)$. Additional islet abnormalities observed in a subset of CF pancreata in (H) donor 6 : $\beta$ cell apoptosis (scale bar: $100 \mu \mathrm{m} ; 20 \mu \mathrm{m}$ [insets]) quantified in Supplemental Figure 7 and (I) intraislet amyloid, as detected by Thioflavin S in 2 of 7 donors (scale bar: $100 \mu \mathrm{m} ; 15 \mu \mathrm{m}$ [insets]). Data represent mean \pm SEM. Statistical significance $(P<0.05)$ was observed in $\beta$ cell area and $\alpha$ cell ratio where noted by the asterisk. Unpaired 2 -tailed Student's $t$ test was used for statistical analysis. The squares and dots represent individual donors and are color coded according to CF donor (Table 1 ).

\section{Discussion}

The increasing prevalence of CFRD, its effect on CF patients, and the recent suggestion that CFTR regulates islet hormone secretion have made the etiology of CFRD a subject of intense scrutiny. Studies of CFTR in islet cell lines $(12,14,16)$, ferret/rodent islets $(11-13,15,16,20,25,35)$, human islets $(11,15)$, and CF patients $(18,21,22,24,26-28,52)$ have suggested that intrinsic dysregulation of $\alpha$ and $\beta$ cell secretion and/or islet loss caused by pancreatic destruction contribute(s) to CFRD pathogenesis. Importantly, islet-intrinsic CFTR regulation of insulin and glucagon secretion by $\alpha$ and $\beta$ cells would identify new mechanisms regulating islet hormone secretion and represent a targetable pathway for CFRD treatment. 
A

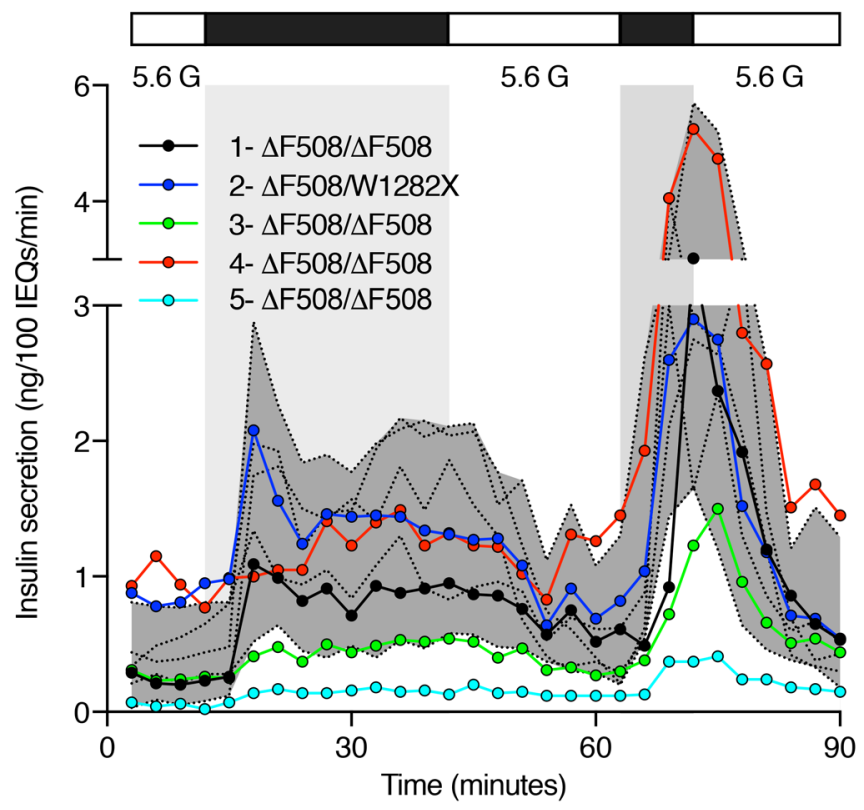

C

$16.7 \mathrm{G}$

IBMX

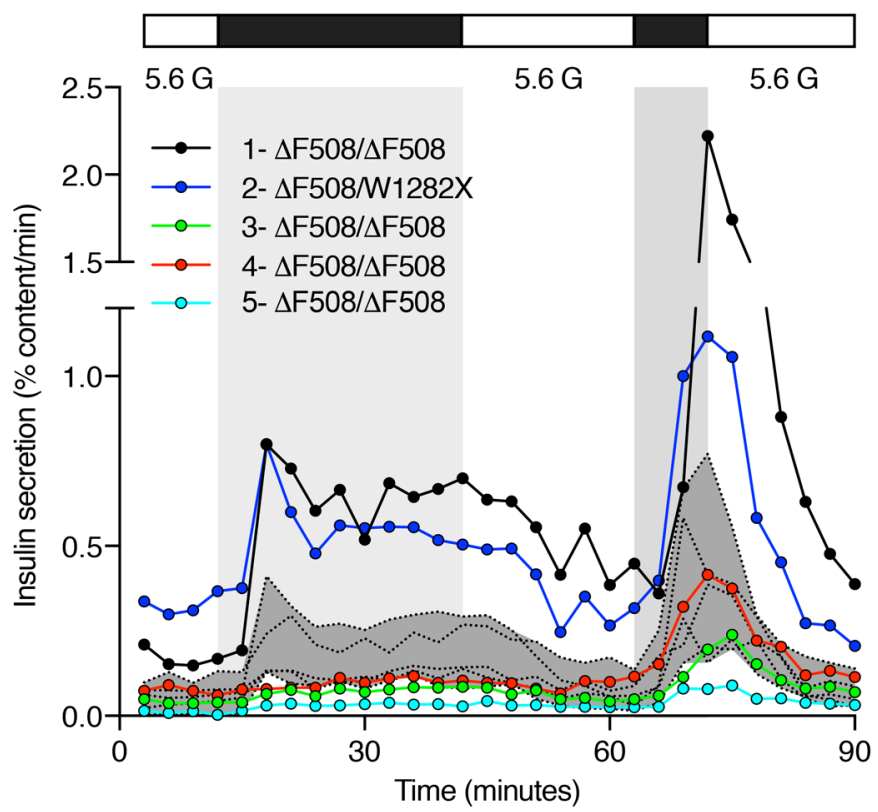

E

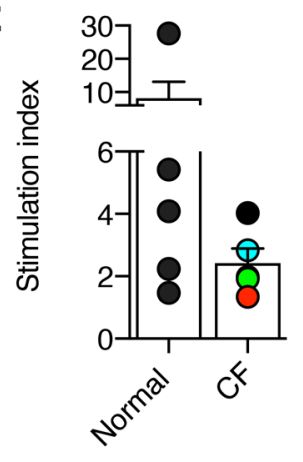

$16.7 \mathrm{G}$

$\mathrm{BMX}$

$6.7 \mathrm{G}+$

$\mathbf{F}$

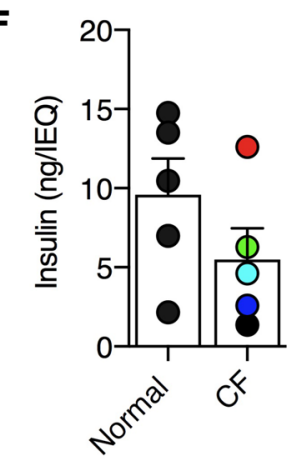

B

16.7 G

$16.7 \mathrm{G}+$

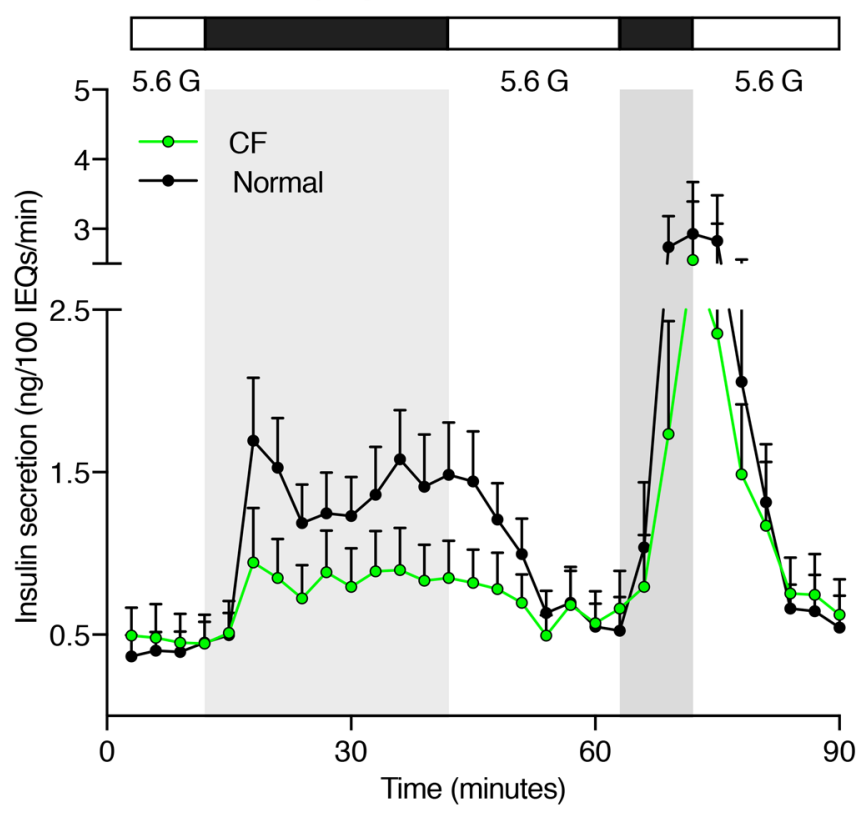

D

$16.7 \mathrm{G}$

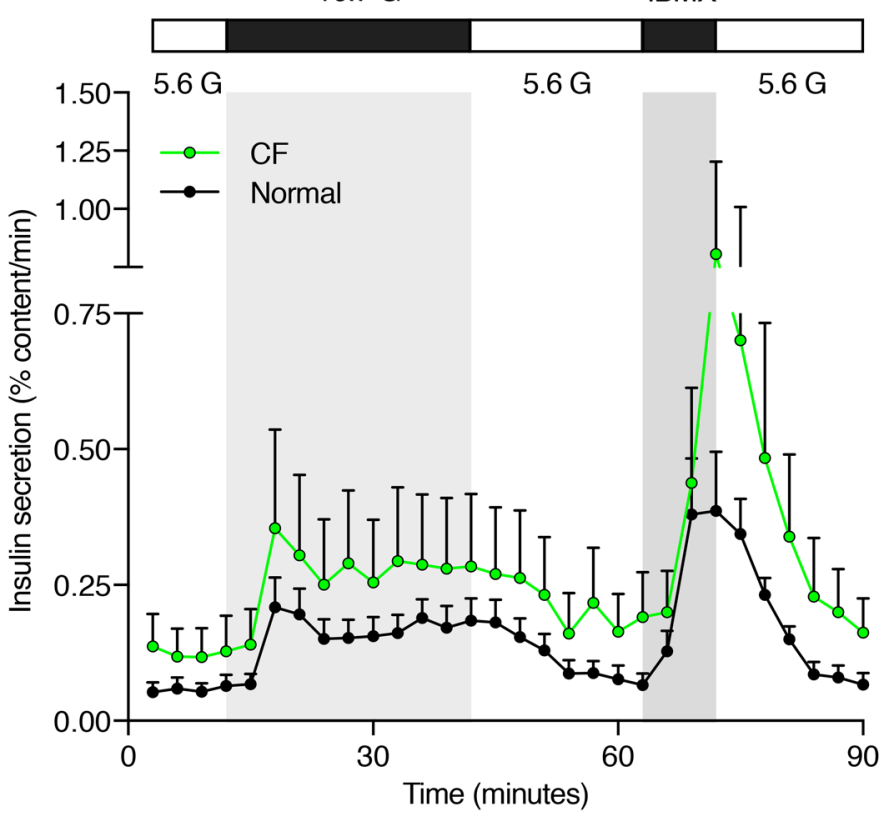


Figure 5. CF islet insulin content, glucose-stimulated insulin secretion, and islet gene expression were similar to healthy control islets. Individual donor (A) and mean (B) insulin secretion perifusion traces of CF islets $(n=5)$ compared with normal islets (shaded area, dotted black lines, $n=5)$ normalized to islet equivalents (IEQ). Individual donor (C) and mean (D) insulin secretion perifusion traces of CF islets $(n=5)$ compared with normal islets (shaded area, $n=5$ ) normalized to insulin content. Entire perifusion traces are in Supplemental Figure 8. Stimulation index (E) comparing the ratio of $16.7 \mathrm{G} / 5.6 \mathrm{G}$ insulin secretory rates. (F) Islet insulin content and (C) whole-islet fold changes of key islet regulatory transcripts in CF islets $(n=5)$ relative to whole healthy islets $(n=5)$. Data represent mean \pm SEM. No statistical difference $(P<0.05)$ was detected using an unpaired 2-tailed Student's $t$ test in $\mathbf{E}$ and $\mathbf{F}$. Ordinary 2 -way ANOVA was used to compare islet perifusions and is discussed in the text. The dots represent individual donors and are color coded according to CF donor (Table 1).

Because there is limited and contradictory information regarding CFTR expression and function in islets, we used two murine models of $\beta$ cell CFTR deletion as well as healthy and CF pancreata and islets to study expression of CFTR in human islets, whether CFTR controls islet hormone secretion, and CF pancreas and islet pathology. Specific deletion of CFTR from $\beta$ cells in two murine models did not alter glucose tolerance or in vitro $\beta$ cell function, indicating CFTR is not involved in murine $\beta$ cell stimulus-secretion coupling. Studies of normal human pancreata and islets found that expression of CFTR mRNA was minimal and that CFTR protein and function were not detectable in islet endocrine cells. We also report for the first time to our knowledge that in vitro insulin and glucagon secretion by human CF/CFRD islets was similar to normal human islets and the CF/CFRD islet-regulatory transcriptome was essentially intact. In addition, we observed profound pancreatic pathology in human CF donors (observed by others, refs. 17, 18, $44,53,54)$ with loss of $\beta$ cell area, islet dysmorphia, and now reported details of islet-infiltrating immune cells. These studies demonstrate that CFTR does not directly regulate insulin or glucagon secretion and that CFRD is primarily caused by pancreatic damage, intraislet inflammation, in vivo islet dysfunction, and islet loss in the setting of a progressive multiorgan disease (Figure 7).

In CF murine models, complete loss of $\beta$ cell function with impaired animal glucose tolerance (12) and preserved $\beta$ cell function with age-related $\beta$ cell loss and worsening glucose tolerance (25) have both been reported. In the $\mathrm{CF}$ ferret model, which recapitulates the pancreatic exocrine pathology of human $\mathrm{CF}$ (CF mice do not, ref. 54), impaired glucose and mixed meal intolerance and impaired islet function have been consistently shown $(13,20,35)$. However, reduced $\beta$ cell mass $(13,20,25)$, fluctuating insulin resistance (25), pancreatic inflammation (20), and an unidentified exocrine-derived paracrine factor (35) have been reported and linked to nutrient intolerance and $\beta$ cell dysfunction in these models. In the single report that concluded that $\beta$ cell CFTR loss in CF mice caused $\beta$ cell dysfunction and impaired glucose tolerance, $\beta$ cell mass and insulin sensitivity were not examined (12). Our murine models of $\beta$ cell-specific CFTR deletion allowed us to determine whether the CFTR contributes directly to $\beta$ cell function without metabolic and pancreatic abnormalities caused by whole-animal CFTR loss. Integrating our data with other reports $(20$, 25,35 ) indicates that nutrient intolerance and $\beta$ cell dysfunction in CF models were not caused directly by $\beta$ cell CFTR loss but by other effects (i.e., insulin resistance, $\beta$ cell loss, pancreas/islet inflammation) caused by whole-animal CFTR deletion.

In vitro experiments using CFTR inhibitors have also been used to ascribe a role for CFTR in the intrinsic control of $\beta$ cell secretory function. In murine islets, one study reported complete loss of in vitro GSIS (12), while another reported maintenance of in vitro GSIS with a reduction in pGSIS (11). In ferret islets, CFTR(inh)-172 caused $\beta$ cell dysfunction in both wild-type and CFTR-knockout ferret islets, indicating nonspecific effects of this CFTR inhibitor (35). One study of $\beta$ cell CFTR function has used human islets, was dependent on the use of CFTR inhibitors, and found only impaired pGSIS with no effect on basal or GSIS (11). Recent evidence has shown that CFTR inhibitors cause inhibition of CFTR-independent chloride currents (55), cellular toxicity (55), increased production of reactive oxygen species, and reduction of mitochondrial membrane potential (56). This suggests that the use of CFTR inhibitors has limitations in determining if CFTR intrinsically controls $\beta$ cell function. By taking care to limit the exposure of human islets to the inhibitor, with no preincubation period, we did not detect CFTR-mediated chloride currents in human $\beta$ cells. In vitro human islet insulin secretion in the presence of specific CFTR modulators (VX770, VX661, VX809) was not changed. These studies differ from the conclusion of a small pilot study in humans, suggesting that ivacaftor (VX770) directly improves in vivo $\beta$ cell secretory function in individuals with CF (52). An alternative explanation is that ivacaftor ameliorates CF pathophysiology in other tissues, leading to clinical improvement and indirectly improving insulin secretion and glucose tolerance. Taken together, these data suggest that CFTR does not intrinsically regulate human $\beta$ cell insulin secretion.

The CFTR transcript was minimally expressed (and in most cells undetectable) and CFTR protein was not detected in islet endocrine cells. These results contrast with those of previous studies reporting CFTR 


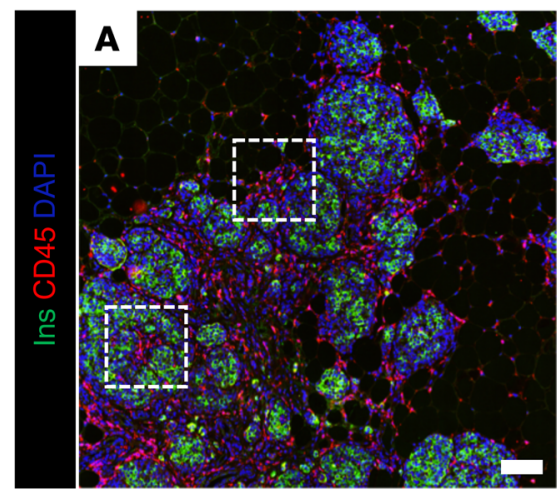

C

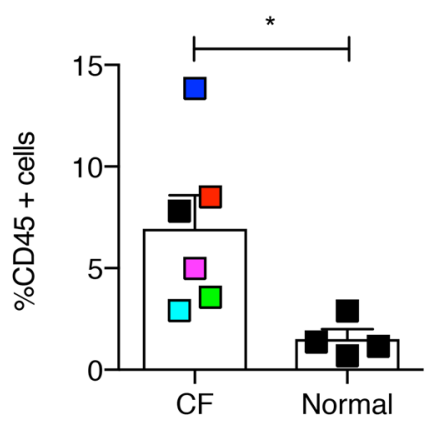

$\mathbf{E}$
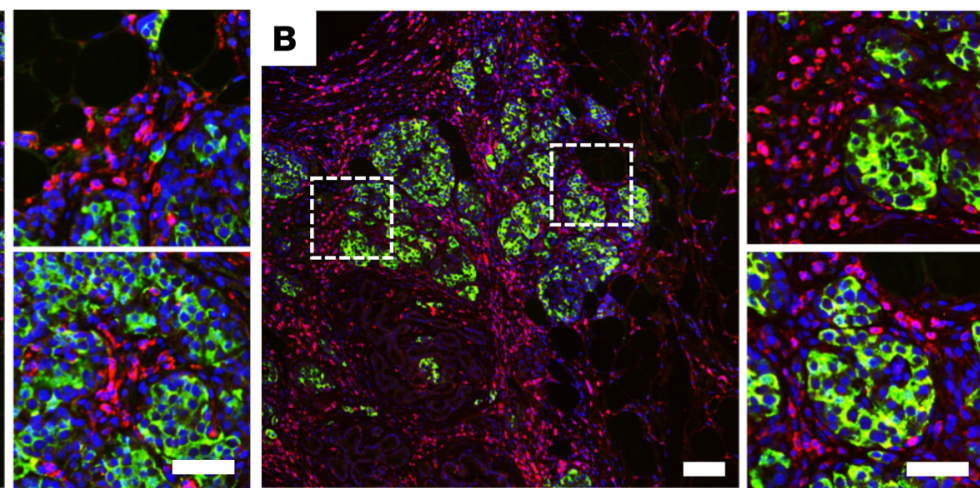

D

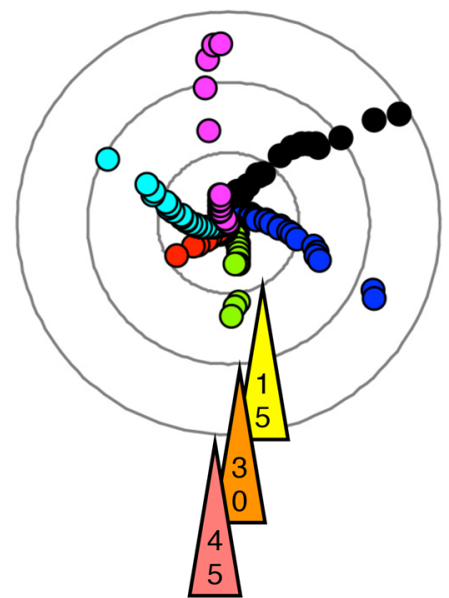

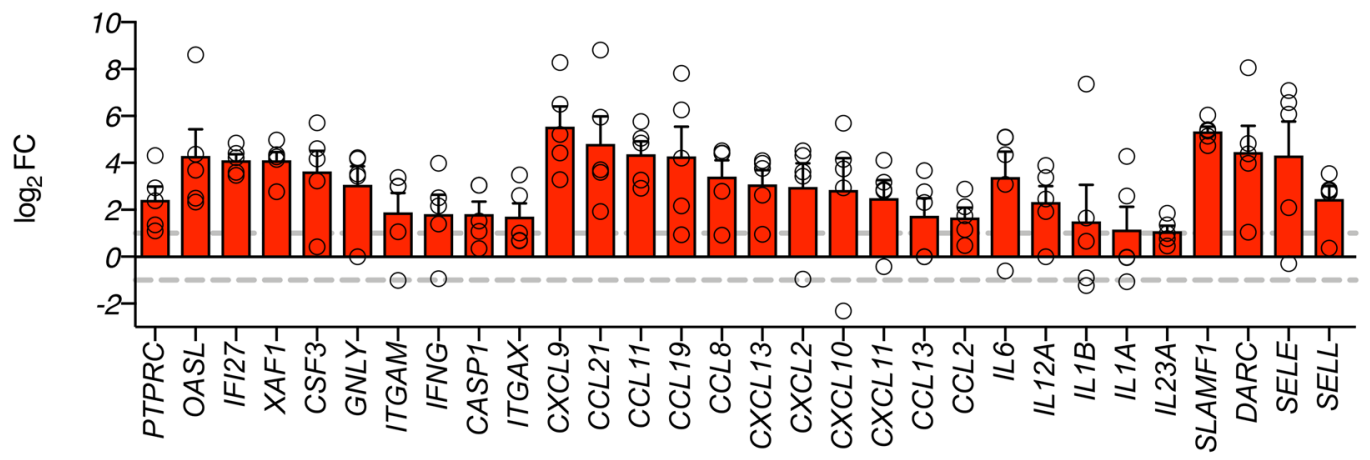
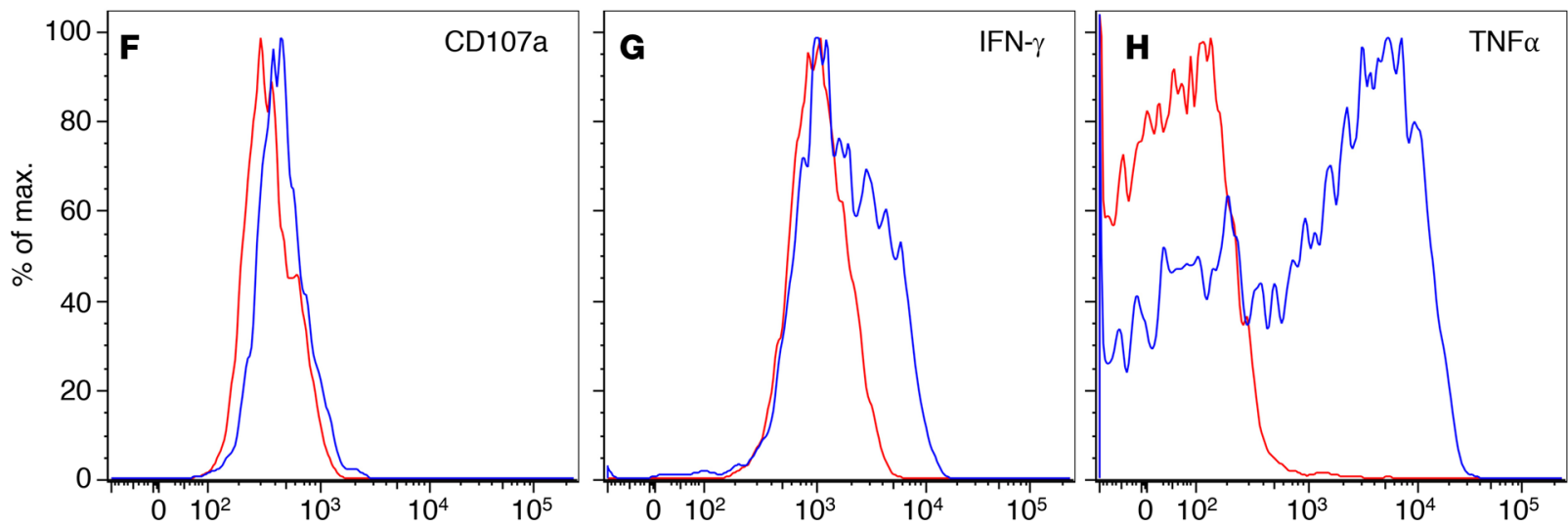

Figure 6. CF pancreas and islets showed marked immune infiltration. CD45 (red) and insulin (green) labeling of CF pancreata from (A) donor 1 and (B) donor 2. Magnification of boxed areas shows populations of $C D 45^{+}$cells at the periphery and within islets (scale bars: $100 \mu \mathrm{m} ; 50 \mu \mathrm{m}$ [insets]). (C) Percentage contribution of CD45 cells to CF and normal pancreata. (D) Number of CD45 cells identified within $20 \mu \mathrm{m}$ of islets ( $n=25$ islets/donor) from CF donors $(n=6)$. The dots represent individual islets and are color-coded according to CF donor (Table 1). Each concentric circle represents the number of immune cells within $20 \mu \mathrm{m}$ of the islet, and each arrow indicates the number of immune cells in that concentric circle. The number increases outward. 
(E) Selected immune-related genes from whole-islet RNA sequencing of CF donors $(n=5)$ versus healthy donors $(n=5)$. T cell lines grown from donor 5 islets were stimulated with and without soluble anti-CD3 overnight and soluble anti-CD28, GolgiPlug, and CD107a staining antibody were then added to all wells for 6 hours. Intracellular staining of a representative CD8 ${ }^{+}$T cell line is shown for (F) CD107a, (G) IFN- $\gamma$, and (H) TNF- $\alpha$. Data represent mean \pm SEM. Statistical significance $(P<0.05)$ was observed in the percentage of pancreatic CD45+ cells indicated by the asterisk. Unpaired 2-tailed Student's $t$ test was used for statistical analysis.

localization to cultured single human $\beta$ and $\alpha$ cells using a relatively concentrated primary antibody (11, 15). Furthermore, the reported labeling of human pancreatic tissue (15) was not accompanied by clear $\alpha$ and $\beta$ cell staining, which would be expected given the reported single cell labeling $(11,15)$ and, importantly, did not show the distinct ductal localization of CFTR. Furthermore, our experiments demonstrating the lack of human islet CFTR expression are supported by electrophysiologic and in vitro insulin secretion experiments, the Human Protein Atlas (43), 3 islet endocrine cell transcriptomes (38-40), and single-molecule fluorescent in situ hybridization (35).

We noted various disruptions in islet morphology, including aggregation of islets, islet cell scattering, and islets with intervening duct-like structures, likely caused by destruction and collapse of the exocrine tissue, and subsequent adipose and fibrotic tissue deposition. Whatever the cause of reduced islet mass and islet dysmorphia, pancreatogenic diabetes has been reported to occur when approximately $65 \%$ of $\beta$ cell area is lost (57), suggesting that the loss of $\beta$ cells observed in our study may be sufficient to cause CFRD.

By obtaining islets from the same pancreata, we also evaluated in vitro hormone secretion and the transcriptome of human CF islets. In contrast to previous reports of impaired $\beta$ cell function in CF models (11-13, 35), we found that human CF islets had appropriate basal insulin secretion and dynamic GSIS, and pGSIS, with insulin secretory profiles and islet insulin content similar to that of 5 age-matched healthy donor islets (Figure 5). In addition, isolated CF islets secreted glucagon in a manner similar to normal islets, with similar islet glucagon content. Importantly, we studied islets with severe CF-causing class I and/or class II CFTR mutations, which are predicted to result in no CFTR or improper protein processing/trafficking (Table 1). CF islets also maintained expression of many key islet-regulatory transcripts, indicating that islet cell identity was preserved. Taken together, these results not only indicate that CFTR does not intrinsically regulate human islet hormone secretion, but that the remnant $\mathrm{CF}$ islets are functional in vitro, which may be clinically significant.

We present for the first time to our knowledge a detailed characterization of an increased inflammatory potential within the human $C F$ islet that is evidenced by increased expression of several cytokines/ chemokines (including IL6, IL1B, CXCL10, TNFA, and IFNG) and high levels of TNF- $\alpha$ and IFN- $\gamma$ production by stimulated $\mathrm{T}$ cells isolated from $\mathrm{CF}$ islets. We postulate that islet isolation from the CF pancreas removes the islet from the inflammatory environment, limiting the effect of cytokines/chemokines, allowing for relatively normal in vitro islet secretion of insulin and glucagon. Thus, we propose that intraislet and islet-proximal immune cells are stimulated in vivo by exocrine tissue destruction and remodeling to produce and secrete chemokines/cytokines, which are known to impair islet secretory function (58).

There are caveats to the current studies. First, our murine models used a conditional exon 11-null allele (36). This null allele may not generate a mutant protein, leading to a hypothesized role of ER stress caused by CF-causing mutations (59). The $\Delta$ F508 mutation alone in mice does not recapitulate the severe CF phenotype observed in humans (60), and, thus, we choose to use an null allele that completely ablates CFTR function, analogous to the CF ferret model $(36,61)$. Furthermore, we have shown that RNA was transcribed without exon 11 in our model (36), which increased our chances of creating $\beta$ cell dysfunction caused by ER stress. Second, our OGTT studies were performed on animals that were conscious, which has the potential to stress animals. Third, we presume pancreatic autolysis also caused the approximately $65 \%$ reduction in $\beta$ cell area. However, we cannot rule out that $\beta$ cell development was affected by CFTR dysfunction, as inhibition of CFTR has been shown to augment endocrine cell development (62) and, recently, $\beta$ deficiency and impaired growth capacity of $\beta$ cells in infants and young children with $\mathrm{CF}$ have been reported (63). Our studies also used CF pancreata and islets from chronically ill individuals taking many medications prior to death. How this influences islet function is not known, but the relatively preserved islet hormone secretion and islet gene expression does not suggest a major impact. We observed a quantitatively variable islet hormone secretion profile from $\mathrm{CF}$ islets, which may reflect differing clinical conditions, levels/persistence of inflammation, and/or islet isolation challenges presented by these pathologic pancreata. Investigating the cause of CFRD in humans is complicated by life-long illness and extensive and complex medical histories; however, no alternative approach appears feasible. 


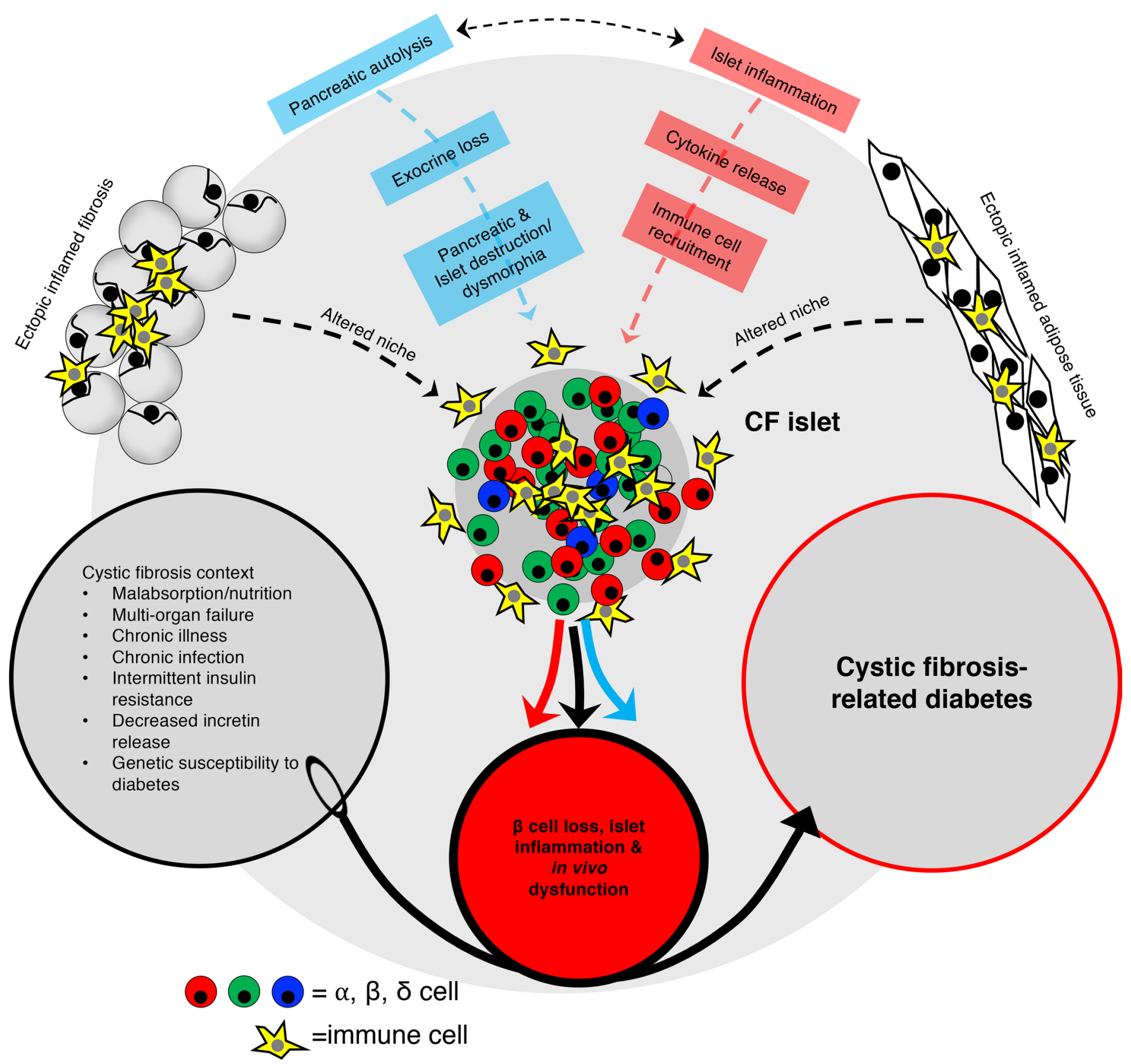

Figure 7. Integrated model of CFRD pathogenesis. Pancreatic autolysis and remodeling results in destruction of the islet niche and environment, $\beta$ cell loss, and immune infiltration. Islet loss and inflammation combined with the numerous physiological derangements observed in CF, particularly those responsible for nutrient assimilation, lead to insulin insufficiency and CFRD.

We postulate that the aforementioned factors combined with metabolic and nutrient-signaling derangements caused by malnutrition/malabsorption $(21,23,64,65)$, gastrointestinal impairments, multiorgan failure, chronic illness, chronic infection (66), and intermittent insulin resistance overlaid on genetic diabetic susceptibility (9) combine to cause insufficient in vivo insulin secretion and CFRD (Figure 7).

Importantly, our studies indicate that remaining islets in CF/CFRD are functional, highlighting the importance of efforts to limit pancreatic destruction and inflammation. Additionally, treatment with agents that improve $\beta$ cell function and/or islet health, such as GLP1R agonists, might be considered for prevention and treatment of CFRD. Our studies also suggest that new modulators of CFTR function do not directly affect $\beta$ cell function, but their ability to improve overall health or limit pancreatic exocrine inflammation and pathology may lead to improved diabetes management. Furthermore, continued investigation of CFRD may provide important insights into islet resiliency, pancreatic 
exocrine-endocrine interaction, and islet-nutrient signaling axes, which may be applicable to the treatment of all forms of diabetes.

\section{Methods}

Generation of $\beta$ cell Cftr deletion models. A model of inducible and $\beta$ cell-specific excision of exon 11 $\left(\beta^{411}\right)$ was generated by crossing female mice heterozygous for a conditional ( $C f t r{ }^{t m l C w r}$, also known as $C f t r^{F L 11}$ ) and null $C f t r$ exon $11\left(C f t r^{\Delta 11}\right.$ ) (from M. Drumm, Case Western Reserve University) (36) with heterozygous $C f t r r^{F L 11} / C f t r^{\Delta 11}$ male mice carrying a B6.Cg-Tg(Ins1-cre/ERT)1Lphi/J (MIPCre ${ }^{\text {ERT }}$ ) transgene (from L. Phillipson, University of Chicago, Chicago, Illinois, USA) (67), both on a C57/BL6 background. Importantly, Cftr exon 10 is "legacy nomenclature" for Cftr exon 11 and was used in the initial description of the animal (36). Cftr ${ }^{\text {FL11 } / C f t r}{ }^{\triangle 11}$ MIPCre ${ }^{\text {ERT }}$ animals were given 3 subcutaneous injections of $6 \mathrm{mg}$ tamoxifen (MilliporeSigma) over 5 days to induce exon 11 recombination or injected with vehicle (V) and allowed to recover for at least 2 weeks (68). To achieve maximal Cftr exon 11 recombination, we focused on heterozygous Cftr ${ }^{F L 11} / C_{f t r}{ }^{\Delta 11}$ MIPCre ${ }^{\text {ERT }}$ animals. Homozygous $C f t r{ }^{\text {FL11 }}$ $\operatorname{MIPCre}^{\mathrm{ERT}}\left(\beta^{\Delta 11^{*}}\right)$ and control mice $(\mathrm{V})$ were also investigated (Supplemental Figure 2). Mice with pancreatic/constitutive deletion of Cftr exon 11 (Panc ${ }^{411}$ ) were generated by crossing $C f t r{ }^{F L 11}$ and wildtype exon 11 allele $\left(C f t r^{w t}\right)$ heterozygous female mice to heterozygous $C f t r^{F L 11} / C f t r^{w t}$ males carrying the B6.FVB-Tg(PDX1-cre)6Tuv/J (PDXCre ${ }^{\text {tuv }}$ ) transgene (purchased from the Jackson Laboratory) (69). Both models and analyses are summarized in Figure 1, A and B. In the $\beta$ cell-specific/inducible model, pretreatment (Pre- $\mathrm{T}_{\mathrm{x}}$ ) animals were 8-14 weeks old and $\mathrm{V}$ and $\beta^{411}$ animals were 12-19 weeks old. Panc ${ }^{411}$ and Panc wt animals were 9-25 weeks of age. By RNA sequencing, $\beta^{411}$ animals showed near $100 \%$ reduction in whole-islet Cftr exon 11 expression (Supplemental Figure 1A). In Panc ${ }^{\Delta 11}$ animals, we found no Cftr exon 11 expression, which was also absent in Panc ${ }^{\text {wt }}$ islets (Supplemental Figure 1G). OGTT and islet studies were performed on both male and female mice.

OGTT. OGTT was performed after a 6-hour fast on conscious animals. Plasma glucose was measured from whole blood, taken from the tail, with an Accu-chek glucose meter (Roche Diagnostics) prior to and $15,30,60,90,120$, and 150 minutes after oral gavage of a $2 \mathrm{~g} / \mathrm{kg}$ glucose bolus.

Mouse islet isolation and measurement of islet insulin secretion and $\mathrm{Ca}^{2+}$. Mouse islets, isolated as previously described (70), were hand picked under microscope guidance and cultured overnight in DMEM (MilliporeSigma) supplemented with $5.6 \mathrm{mM}$ glucose, 10\% FBS (Millipore) and 1\% Penicillin/Streptomycin (Gibco) at $37^{\circ} \mathrm{C}$. Islets from experimental and control animals were size matched into 3 replicates and placed on Millicell Cell Culture Inserts (Millipore) in nontissue-treated 24-well plates. Islets were equilibrated in DMEM supplemented with $5.6 \mathrm{mM}$ glucose for 45 minutes at $37^{\circ} \mathrm{C}$ and then incubated for 1 hour at $37^{\circ} \mathrm{C}$ in $5.6 \mathrm{mM}$ glucose, $16.7 \mathrm{mM}$ glucose, and $16.7 \mathrm{mM}$ glucose plus $100 \mu \mathrm{M}$ 3-isobutyl-1-methylxanthine (MilliporeSigma). The slightly higher basal glucose concentration $(5.6 \mathrm{mM})$ compared with some other studies (e.g., $1 \mathrm{mM}$ or $2.8 \mathrm{mM}$ ) was used to ensure uniformity between mouse and human studies. This is the reason the reported fold changes were observed. After each incubation, media were collected, and upon assay completion, islets were incubated in acid ethanol for at least 48 hours at $4^{\circ} \mathrm{C}$ and the supernatant was collected. All samples were stored at $-80^{\circ} \mathrm{C}$ until insulin measurement by radioimmunoassay from Millipore (catalog no. RI-13K) $(32,71)$.

For measurement of intracellular $\mathrm{Ca}^{2+}$, islets were isolated from $\beta^{411}$ and control animals, dispersed into single cells with trituration in $0.005 \%$ trypsin (Gibco), cultured overnight at $37^{\circ} \mathrm{C}$ in RPMI 1640 (Gibco) supplemented with $11 \mathrm{mM}$ glucose, 10\% FBS, and 1\% Penicillin/Streptomycin. Dispersed single cells were incubated for 20 minutes at $37^{\circ} \mathrm{C}$ in RPMI containing $2 \mu \mathrm{M}$ Fura-2AM (Molecular Probes), followed by incubation with Krebs-Ringer bicarbonate buffer with $2 \mathrm{mM}$ glucose for 20 minutes. $\mathrm{Ca}^{2+}$ imaging was performed as previously described (72).

Islet isolation from human CF pancreata. Pancreata from clinically diagnosed CF donors were identified via the International Institute for the Advancement of Medicine (IIAM) or National Disease Interhange (NDRI) and shipped to the Institute of Cellular Therapeutics at the Allegheny Health Network (Pittsburgh, Pennsylvania, USA) or the University of Louisville for islet isolation (Table 1). Islet isolation was carried out according to a modification of the method described by Ricordi et al. (73, 74). Digestive exogenous enzyme was injected into the duct and a stationary digestion was followed by mechanical and enzymatic digestion prior to tissue disruption and collection. Islets were resuspended in Connaught Medical Research Laboratories 1066 medium (Mediatech) supplemented with 10\% heat-inactivated FCS, 
100 units/ml Penicillin, $0.1 \mathrm{mg} / \mathrm{ml}$ Streptomycin, and $2 \mathrm{mmol} / \mathrm{L}$ L-glutamine (Life Technologies) (75); cultured overnight at the isolation center; and shipped overnight to Vanderbilt.

Control human islets were obtained through the Alberta Diabetes Institute IsletCore Program and the Integrated Islet Distribution Program and also isolated from normal pancreata obtained from the IIAM or NDRI by our team at the Allegheny Health Network. Human islet patch clamp experiments and static insulin secretion experiments were performed at the University of Alberta, and islet perifusions were performed at Vanderbilt. A detailed summary of human pancreas and islet donors is presented in Supplemental Spreadsheet 1.

Patch-clamp electrophysiology. For recording of $\beta$ cell currents, fire-polished patch pipettes (Sutter Instruments) with a tip resistance of 4-7 M $\Omega$ were used for patch clamp recordings in the perforated-patch configuration, using a EPC10 amplifier and Patchmaster software (HEKA Electronik). The bath solution was composed of $140 \mathrm{mM} \mathrm{NaCl}, 3.6 \mathrm{mM} \mathrm{KCl}, 0.5 \mathrm{mM} \mathrm{MgSO}_{4}, 1.5 \mathrm{mM} \mathrm{CaCl}_{2}, 10 \mathrm{mM}$ HEPES, $0.5 \mathrm{mM}$ $\mathrm{NaH}_{2} \mathrm{PO}_{4}, 5 \mathrm{mM} \mathrm{NaHCO}$, and $1 \mathrm{mM}$ glucose ( $\mathrm{pH}$ adjusted to 7.4 with $\mathrm{NaOH}$ ). The pipette solution contained $76 \mathrm{mM} \mathrm{K}_{2} \mathrm{SO}_{4}, 10 \mathrm{mM} \mathrm{KCl}, 10 \mathrm{mM} \mathrm{NaCl}, 1 \mathrm{mM} \mathrm{MgCl}, 5 \mathrm{mM} \mathrm{HEPES}$, and $0.24 \mathrm{mM} \mathrm{mg} /$ $\mathrm{ml}$ amphotericin $\mathrm{B}$ ( $\mathrm{pH}$ adjusted to 7.3 with $\mathrm{KOH}$ ). Cells were continuously perifused with bath solution at approximately $1 \mathrm{ml} / \mathrm{min}$ and $32^{\circ} \mathrm{C}$. Rapid application of $10 \mu \mathrm{M}$ forskolin, $10 \mu \mathrm{M}$ forskolin plus $20 \mu \mathrm{M}$ CFTR(inh)-172 (from the CFF), or control (bath solution only) was performed using a Fast-Step system (Warner Instruments). For positive control detection of CFTR chloride currents, INS 832/13 cells (from C. Newgard at Duke University, Durham, North Carolina, USA) were transfected with plasmid vectors expressing either human CFTR and GFP or GFP alone using Lipofectamine 2000. In human islet experiments, $\beta$ cells were identified by immunostaining for insulin after patch clamping.

Human islet insulin secretion measurements. Human islets were perifused within 24 hours of arrival at Vanderbilt, as previously described $(32,71,76)$, with DMEM supplemented with the following glucose concentrations and test agents: $5.6 \mathrm{mM}$ glucose, $16.7 \mathrm{mM}$ glucose, $16.7 \mathrm{mM}$ glucose plus $100 \mu \mathrm{m}$ IBMX, $1.7 \mathrm{mM}$ glucose plus $1 \mu \mathrm{m}$ epinephrine (MilliporeSigma), and $5.6 \mathrm{mM}$ glucose plus $20 \mathrm{mM} \mathrm{KCl}$ (MilliporeSigma). Human insulin and glucagon secretion and content was measured in fractions and extracts by radioimmunoassay from MilliporeSigma (catalog no. RI-13K and GL-32K) (32, 71). Data were normalized to IEQ, total content, maximum $\mathrm{KCl}$ response, maximum IBMX response, and in the case of glucagon, $1.7 \mathrm{mM}$ glucose $+1 \mu \mathrm{m}$ epinephrine. A glucose stimulation index (ratio of $16.7 \mathrm{mM}$ glucose to $5.6 \mathrm{mM}$ glucose secretion rates) was also calculated for perifusions. Human islet static insulin secretion measurements were performed at the University of Alberta as previously described (77). The VX compounds were obtained from the CFF.

CFTR mutation identification. Genomic DNA was purified from flash frozen pancreatic tissue using the Wizard Genomic DNA Purification Kit (Promega). DNA analysis to identify CF-causing CFTR variants was performed by the Genetics Translational Technology Core at Johns Hopkins University. DNA samples were genotyped using a custom CFTR MassARRAY assay designed to screen for 159 disease-associated CFTR variants (78) and according to Johns Hopkins DNA Diagnostic Lab standard clinical operating procedures (Agena Bioscience). In one case, next-generation sequencing with custom SureSelect library preparation (Agilent) and MiSeq sequencing (Illumina) were used to assess for variants in the coding regions and flanking introns of CFTR.

Murine and human islet $R N A$ sequencing. Both murine and human islets were hand picked under microscope guidance, washed with PBS, and immediately frozen at $-80^{\circ} \mathrm{C}$. Islet RNA was extracted (79) using the RNAqueous Micro-Total RNA Isolation Kit (Ambion/Invitrogen). Trace contaminating DNA was removed with TURBO DNA-free (Ambion/Invitrogen). RNA quality control quantification was performed using a Qubit Fluorometer (Invitrogen) and an Agilent 2100 Bioanalyzer. All RNA samples had an RNA integrity number $\geq 6.0$. RNA was amplified using the NuGEN Technologies Ovation RNA amplification kit, which was optimized for RNA sequencing. Following amplification, the resulting cDNA was sheared to an average insert size of $300 \mathrm{bp}$ and used for library preparation. Sequencing was performed using standard Illumina methods as described previously $(80,81)$. Following RNA sequencing, raw reads were mapped to reference mouse or human genome as appropriate using TopHat v2.0 (82). Aligned reads were imported onto the Avadis NGS data analysis platform (Strand Scientific Intelligence, Bengalor). Reads were first filtered on their quality metrics, and then duplicate reads were removed. Normalized gene expression was quantified using the TMM (trimmed mean of M values) algorithm $(83,84)$. The transcriptional profile from each sample group was compared by principle component analysis and hierarchal clustering 
analysis to determine the layout and spread of the samples. Differential expression between conditions was calculated on the basis of fold change (cutoff $\geq 2.0$ ), and the $P$ value was estimated by $Z$-score calculations (cutoff 0.05), as determined by the Benjamini-Hochberg false discovery rate method (85). Differentially expressed genes underwent gene set enrichment analysis, gene ontology analysis, and pathway analysis using DAVID and Ingenuity pathway analysis. Sequencing data are available on the Gene Expression Omnibus repository (accession GSE110935).

Pancreatic tissue immunochemistry. Prior to islet isolation at the Allegheny Health Network and the University of Louisville, samples from the pancreatic head, body, and tail were flash frozen and prepared for cryosectioning and paraffin sectioning. For cryosections, pancreatic samples were fixed in ice-cold $4 \%$ paraformaldehyde (Electron Microscopy Sciences) in 0.1 M PBS for 3 hours on ice under mild agitation. The tissue was washed with $0.1 \mathrm{M}$ PBS and incubated overnight in $30 \%$ sucrose at $4^{\circ} \mathrm{C}$ and embedded in a cryomold using Optimal Cutting Temperature compound (Tissue-Tek) and stored at $-80^{\circ} \mathrm{C}$. For paraffin sections, the pancreas was fixed in 10\% neutral buffered formalin and shipped to Vanderbilt overnight. Upon arrival at Vanderbilt, the pancreatic fragments were washed in $70 \%$ ethanol and embedded in paraffin.

Five- $\mu \mathrm{m}$ tissue sections were washed in PBS followed by permeabilization with $0.2 \%$ Triton X (Bio$\mathrm{Rad}$ ), blocked with normal donkey serum (Jackson ImmunoResearch), incubated overnight at $4^{\circ} \mathrm{C}$ with primary antibodies (Supplemental Table 4), incubated with secondary antibodies (Jackson ImmunoResearch), and counterstained with DAPI (Invitrogen) and mounted, as previously described (86). Cryosections were equilibrated to room temperature; paraffin-embedded sections were dewaxed/rehydrated, heated in sodium citrate buffer, and rinsed in $\mathrm{diH}_{2} \mathrm{O}$ prior to staining. TUNEL labeling was performed on formalin-fixed/paraffin-embedded sections according to the manufacturer's instructions (Millipore).

Whole-tissue sections were imaged with an Aperio FL Scanscope (Leica Biosystems). Customized Cytonuclear FL v1.3 cell counting algorithms (Indica Labs) on the HALO platform were used to count islet endocrine cell populations ( $\alpha, \beta, \delta$ cells), $\mathrm{TUNEL}^{+}$and insulin ${ }^{+}$cells, $\mathrm{Ki}^{+} 7^{+}$and insulin ${ }^{+}$cells, and $\mathrm{CD}^{2} 5^{+}$cells. Ratios of islet endocrine cells were determined by dividing the number of the individual cell type $(\alpha, \beta$, or $\delta$ ) by the total number of endocrine cells $(\alpha, \beta$, and $\delta)$. $\beta$ Cell apoptosis and proliferation were calculated by dividing the number of $\mathrm{TUNEL}^{+}$or $\mathrm{Ki}^{2} 7^{+}$and insulin ${ }^{+}$cells, respectively, by the total number of insulin ${ }^{+}$cells. The number of $\mathrm{CD}_{4} 5^{+}$cells was divided by the total number of $\mathrm{DAPI}^{+}$cells to determine the contribution of immune cells to the pancreatic tissue. The number of cells counted is summarized in Supplemental Tables 5-8.

$H \& E$ labeling and $\beta$ cell area measurement. Pancreatic sections were stained with $H \& E$ or labeled with insulin and visualized using a DAB (Vector Laboratories) stain with a hematoxylin counterstain. Images of the entire section were captured using an Aperio ScanScope CS (Leica Biosystems). Analysis of $\beta$ cell area was performed on whole pancreatic sections using customized Tissue Classifiers (Indica Labs) generated in Halo (Leica Biosystems). $\beta$ Cell area was determined by dividing the $\beta$ cell classified area by the total classified area. The classified area is summarized in Supplemental Table 9.

CF islet T cell isolation, stimulation, and intracellular staining. Live hand-picked islets from donor 5 were dissociated and immediately stained with viability dye and $\mathrm{T}$ cell markers, which were used to detect $\mathrm{T}$ cell populations by flow cytometry. The gate was set for single cells, viable cells, $\mathrm{CD}^{+}$cells, and then for $\mathrm{CD} 4^{+}$and $\mathrm{CD} 8^{+}$ cells. Cells in the $\mathrm{CD}^{+}$gate were then interrogated for $\mathrm{CD} 45 \mathrm{RA}$. CD8 ${ }^{+} \mathrm{CD} 45 \mathrm{RA}{ }^{+} \mathrm{T}$ cells were interrogated for CCR7 and CD62L. CD8 ${ }^{+} \mathrm{CD} 45 \mathrm{RA}^{+} \mathrm{CCR} 7^{+} \mathrm{CD} 62 \mathrm{~L}^{+} \mathrm{T}$ cells were then interrogated for $\mathrm{CD} 27 . \mathrm{CD} 8^{+} \mathrm{C}-$ $\mathrm{D}_{45 \mathrm{RA}^{-}} \mathrm{T}$ cells were interrogated for CCR7 and CD62L, as summarized in Supplemental Figure 14.

Islets from donor 5 were plated on a gel matrix with $\mathrm{T}$ cell stimulation and growth factors, and, after approximately 10 days, cells growing around islets were collected and expanded as previously described (50). T cell lines in early passages (passage 1-3) were left unstimulated or stimulated by adding the cells onto wells coated with anti-CD3 $(10 \mu \mathrm{g} / \mathrm{ml})$ overnight at $4^{\circ} \mathrm{C}$. Soluble anti-CD28 $(2 \mu \mathrm{g} / \mathrm{ml})(B D$ Biosciences), and GolgiPlug (BD BioSciences) were added to all conditions, and CD107a staining antibody was added to all wells and incubated at $37^{\circ} \mathrm{C}$ for 6 hours. HL-1 media, supplemented with $2 \mathrm{mM} \mathrm{L-glutamine,} 5$ $\mathrm{mM}$ HEPES, and $100 \mathrm{U} / \mathrm{ml}$ Penicillin, $100 \mu \mathrm{g} / \mathrm{ml}$ Streptomycin, $0.1 \mathrm{mM}$ of each nonessential amino acid, and $1 \mathrm{mM}$ sodium pyruvate (all from Lonza) and 5\% heat-inactivated human male AB serum (Omega Scientific), was used in all experiments. Cells were then stained with a viability dye as per manufacturer's instructions (Live Dead Aqua, Thermofisher) and stained for CD3, CD4, and CD8 $\alpha$ or CD8 $\beta$ surface markers (BD Biosciences). Cells were fixed, permeabilized (BD Cytofix/Cytoperm, BD Biosciences), and stained for the intracellular cytokines, IFN- $\gamma$ and TNF- $\alpha$. Stained cells were run on a BD LSRII, collecting between 30,000-50,000 events, and analyzed with FlowJo software (v.9). 
Statistics. One-way ANOVA followed by Tukey multiple-comparisons test and unpaired 2-tailed Student's $t$ test were used to compare outcomes in mice of different genotypes. Unpaired 2-tailed Student's $t$ tests were used to compare human samples with and without CF. An ordinary 2-way ANOVA with a Sidak's multiple comparison test was used to compare CF and normal islet hormone secretion during islet perifusion. A $P$ value of less than 0.05 was considered significant.

Study approval. All animal studies were reviewed and approved by the Institutional Animal Care and Use Committee (IACUC) at Vanderbilt University Medical Center. Mice were housed and cared for according to the Vanderbilt Department of Animal Care and IACUC/Office of Animal Welfare Assurance standards and guidelines. The Vanderbilt University Institutional Review Board declared that studies on deidentified human pancreatic specimens do not qualify as human subject research.

\section{Author contributions}

NJH, MLD, SCK, PEM, and ACP designed research studies. NJH, RA, GP, CF, AHT, AB, AFS, JABB, MED, PKD, and SCK conducted experiments. NJH, AB, AFS, JABB, MED, MB, CD, and SCK acquired data. NJH, WSB, MB, NP, DAJ, SCK, and PEM analyzed data. ANB, RB, SCK, and PEM provided reagents. NJH, SCK, DAJ, PEM, and ACP wrote the manuscript.

\section{Acknowledgments}

We thank Molly Sheridan and Scott Blackman at John Hopkins for their assistance in the identification of CF-causing CFTR mutations. We also thank Chanjuan Shi at Vanderbilt for assistance with pancreatic pathology. This research was performed using resources and/or funding provided by the National Institute of Diabetes and Digestive and Kidney Diseases-supported Human Islet Research Network (RRID:SCR_014393; https://hirnetwork.org) (UC4 DK104211, DK108120, and DK112232); NIH grants DK106755, DK72473, DK89572, DK97829, DK94199, and AI126189; the Vanderbilt Diabetes Research and Training Center (DK20593); and grants from the CFF (RDP DRUMM15R0), JDRF, the Leona M. and Harry B. Helmsley Charitable Trust, the Department of Veterans Affairs, the Cell Imaging Shared Resource and the Islet Procurement and Analysis Core of the Vanderbilt Diabetes Research and Training Center (DK20593), the University of Massachusetts Medical School Flow Cytometry Core Facility, and the Alberta Diabetes Foundation. This research was also performed with the support of the Network for Pancreatic Organ Donors with Diabetes (https://www.jdrfnpod.org/) and the Integrated Islet Distribution Program (https://iidp.coh.org/). We are grateful to Organ Procurement Organizations partnering with the International Institute for Advancement of Medicine and National Disease Research Interchange. We are especially thankful to organ donors and their families. Identification of CF-causing mutations was made possible by grant 1UL1RR025005 from the National Center for Research Resources, a component of the NIH, and NIH Roadmap for Medical Research. The contents are solely the responsibility of the authors and do not necessarily represent the official view of the National Center for Research Resources or the NIH. JABB was supported by JDRF postdoctoral fellowship 3-PDF-201703740A-N, and NJH was supported by the Vanderbilt Research Training in Diabetes and Endocrinology Program grant (5T32 DK007061). Portions of this works have been previously presented at the 76th and 77th American Diabetes Association Scientific Sessions and at the Human Islet Research Network 2017 Annual Investigator Meeting.

Address correspondence to: Alvin C. Powers, Vanderbilt University Medical Center, 7465 Medical Research Building IV, 2215 Garland Avenue, Nashville, Tennessee 37232-0475, USA. Phone: 615.936.7678; Email: al.powers@Vanderbilt.edu.

1. Cystic Fibrosis Foundation Patient Registry 2016 Annual Data Report. Cystic Fibrosis Foundation. https://www.cff.org/ Research/Researcher-Resources/Patient-Registry/2016-Patient-Registry-Annual-Data-Report.pdf. Accessed April 10, 2018.

2. Moran A, et al. Clinical care guidelines for cystic fibrosis-related diabetes: a position statement of the American Diabetes Association and a clinical practice guideline of the Cystic Fibrosis Foundation, endorsed by the Pediatric Endocrine Society. Diabetes Care. 2010;33(12):2697-2708.

3. Marshall BC, Butler SM, Stoddard M, Moran AM, Liou TG, Morgan WJ. Epidemiology of cystic fibrosis-related diabetes. J Pediatr. 2005;146(5):681-687.

4. Gudipaty L, Rickels MR. Pancreatogenic (Type 3c) Diabetes. The Pancreapedia: Exocrine Pancreas Knowledge Base https://doi.org/10.3998/panc.2015.35

5. O'Riordan SM, Robinson PD, Donaghue KC, Moran A, ISPAD Clinical Practice Consensus. Management of cystic fibrosis-re- 
lated diabetes. Pediatr Diabetes. 2008;9(4 Pt 1):338-344.

6. Moran A, et al. Epidemiology, pathophysiology, and prognostic implications of cystic fibrosis-related diabetes: a technical review. Diabetes Care. 2010;33(12):2677-2683.

7. Kelly A, Moran A. Update on cystic fibrosis-related diabetes. J Cyst Fibros. 2013;12(4):318-331.

8. Konrad K, et al. Cystic fibrosis-related diabetes compared with type 1 and type 2 diabetes in adults. Diabetes Metab Res Rev. 2013;29(7):568-575

9. Blackman SM, et al. Genetic modifiers of cystic fibrosis-related diabetes. Diabetes. 2013;62(10):3627-3635.

10. Couce M, O'Brien TD, Moran A, Roche PC, Butler PC. Diabetes mellitus in cystic fibrosis is characterized by islet amyloidosis J Clin Endocrinol Metab. 1996;81(3):1267-1272.

11. Edlund A, Esguerra JL, Wendt A, Flodström-Tullberg M, Eliasson L. CFTR and Anoctamin 1 (ANO1) contribute to cAMP amplified exocytosis and insulin secretion in human and murine pancreatic beta-cells. BMC Med. 2014;12:87.

12. Guo JH, et al. Glucose-induced electrical activities and insulin secretion in pancreatic islet $\beta$-cells are modulated by CFTR. Nat Commun. 2014;5:4420

13. Olivier AK, et al. Abnormal endocrine pancreas function at birth in cystic fibrosis ferrets. J Clin Invest. 2012;122(10):3755-3768.

14. Ntimbane T, et al. CFTR silencing in pancreatic $\beta$-cells reveals a functional impact on glucose-stimulated insulin secretion and oxidative stress response. Am J Physiol Endocrinol Metab. 2016;310(3):E200-E212.

15. Edlund A, Pedersen MG, Lindqvist A, Wierup N, Flodström-Tullberg M, Eliasson L. CFTR is involved in the regulation of glucagon secretion in human and rodent alpha cells. Sci Rep. 2017;7(1):90.

16. Huang WQ, et al. Glucose-sensitive CFTR suppresses glucagon secretion by potentiating KATP channels in pancreatic islet $\alpha$ cells. Endocrinology. 2017;158(10):3188-3199.

17. Iannucci A, Mukai K, Johnson D, Burke B. Endocrine pancreas in cystic fibrosis: an immunohistochemical study. Hum Pathol. 1984;15(3):278-284

18. Löhr M, et al. Cystic fibrosis associated islet changes may provide a basis for diabetes. An immunocytochemical and morphometrical study. Virchows Arch A Pathol Anat Histopathol. 1989;414(2):179-185.

19. Soejima K, Landing BH. Pancreatic islets in older patients with cystic fibrosis with and without diabetes mellitus: morphometric and immunocytologic studies. Pediatr Pathol. 1986;6(1):25-46.

20. Yi Y, et al. A transient metabolic recovery from early life glucose intolerance in cystic fibrosis ferrets occurs during pancreatic remodeling. Endocrinology. 2016;157(5):1852-1865.

21. Sheikh S, et al. Reduced $\beta$-cell secretory capacity in pancreatic-insufficient, but not pancreatic-sufficient, cystic fibrosis despite normal glucose tolerance. Diabetes. 2017;66(1):134-144.

22. Moran A, Diem P, Klein DJ, Levitt MD, Robertson RP. Pancreatic endocrine function in cystic fibrosis. J Pediatr. 1991;118(5):715-723.

23. Perano SJ, et al. Pancreatic enzyme supplementation improves the incretin hormone response and attenuates postprandial glycemia in adolescents with cystic fibrosis: a randomized crossover trial. J Clin Endocrinol Metab. 2014;99(7):2486-2493.

24. Stahl M, Girard J, Rutishauser M, Nars PW, Zuppinger K. Endocrine function of the pancreas in cystic fibrosis: evidence for an impaired glucagon and insulin response following arginine infusion. J Pediatr. 1974;84(6):821-824.

25. Fontés $\mathrm{G}$, et al. The $\Delta \mathrm{F} 508$ mutation in the cystic fibrosis transmembrane conductance regulator is associated with progressive insulin resistance and decreased functional $\beta$-cell mass in mice. Diabetes. 2015;64(12):4112-4122.

26. Lippe BM, Sperling MA, Dooley RR. Pancreatic alpha and beta cell functions in cystic fibrosis. J Pediatr. 1977;90(5):751-755.

27. Wooldridge JL, Szczesniak RD, Fenchel MC, Elder DA. Insulin secretion abnormalities in exocrine pancreatic sufficient cystic fibrosis patients. J Cyst Fibros. 2015;14(6):792-797.

28. Soave D, et al. Evidence for a causal relationship between early exocrine pancreatic disease and cystic fibrosis-related diabetes: a Mendelian randomization study. Diabetes. 2014;63(6):2114-2119.

29. Steiner DJ, Kim A, Miller K, Hara M. Pancreatic islet plasticity: interspecies comparison of islet architecture and composition. Islets. 2010;2(3):135-145.

30. Brissova M, et al. Assessment of human pancreatic islet architecture and composition by laser scanning confocal microscopy J Histochem Cytochem. 2005;53(9):1087-1097.

31. Brissova M, et al. Human islets have fewer blood vessels than mouse islets and the density of islet vascular structures is increased in type 2 diabetes. J Histochem Cytochem. 2015;63(8):637-645.

32. Dai C, et al. Islet-enriched gene expression and glucose-induced insulin secretion in human and mouse islets. Diabetologia. 2012;55(3):707-718

33. Cabrera O, Berman DM, Kenyon NS, Ricordi C, Berggren PO, Caicedo A. The unique cytoarchitecture of human pancreatic islets has implications for islet cell function. Proc Natl Acad Sci USA. 2006;103(7):2334-2339.

34. Benner C, van der Meulen T, Cacéres E, Tigyi K, Donaldson CJ, Huising MO. The transcriptional landscape of mouse beta cells compared to human beta cells reveals notable species differences in long non-coding RNA and protein-coding gene expression. BMC Genomics. 2014;15:620.

35. Sun X, et al. CFTR influences beta cell function and insulin secretion through non-cell autonomous exocrine-derived factors Endocrinology. 2017;158(10):3325-3338.

36. Hodges CA, Cotton CU, Palmert MR, Drumm ML. Generation of a conditional null allele for Cftr in mice. Genesis. 2008;46(10):546-552.

37. Stancill JS, et al. Chronic $\beta$-cell depolarization impairs $\beta$-cell identity by disrupting a network of ca2+-regulated genes. Diabetes. 2017;66(8):2175-2187

38. Segerstolpe $\AA$, et al. Single-cell transcriptome profiling of human pancreatic islets in health and type 2 diabetes. Cell Metab. 2016;24(4):593-607.

39. Blodgett DM, et al. Novel observations from next-generation RNA sequencing of highly purified human adult and fetal islet cell subsets. Diabetes. 2015;64(9):3172-3181.

40. Bramswig NC, et al. Epigenomic plasticity enables human pancreatic $\alpha$ to $\beta$ cell reprogramming. J Clin Invest. 2013;123(3):1275-1284. 
41. Yan-Do R, et al. A glycine-insulin autocrine feedback loop enhances insulin secretion from human $\beta$-cells and is impaired in type 2 diabetes. Diabetes. 2016;65(8):2311-2321.

42. van Meegen MA, et al. CFTR-mutation specific applications of CFTR-directed monoclonal antibodies. J Cyst Fibros. 2013;12(5):487-496

43. Uhlén M, et al. Proteomics. Tissue-based map of the human proteome. Science. 2015;347(6220):1260419.

44. Andersen DH. Cystic fibrosis of the pancreas and its relation to celiac disease - A clinical and pathologic study. Am J Dis Child 1938;56(2):344-399

45. Atkinson MA, et al. How does type 1 diabetes develop?: the notion of homicide or $\beta$-cell suicide revisited. Diabetes. 2011;60(5):1370-1379.

46. Atkinson MA, Eisenbarth GS. Type 1 diabetes: new perspectives on disease pathogenesis and treatment. Lancet. 2001;358(9277):221-229.

47. Donath MY, Shoelson SE. Type 2 diabetes as an inflammatory disease. Nat Rev Immunol. 2011;11(2):98-107.

48. Eguchi K, Nagai R. Islet inflammation in type 2 diabetes and physiology. J Clin Invest. 2017;127(1):14-23.

49. Campbell-Thompson ML, et al. The diagnosis of insulitis in human type 1 diabetes. Diabetologia. 2013;56(11):2541-2543.

50. Babon JA, et al. Analysis of self-antigen specificity of islet-infiltrating T cells from human donors with type 1 diabetes. Nat Med. 2016;22(12):1482-1487.

51. Wang C, Guan Y, Yang J. Cytokines in the progression of pancreatic $\beta$-cell dysfunction. Int J Endocrinol. 2010;2010:515136.

52. Bellin MD, et al. Insulin secretion improves in cystic fibrosis following ivacaftor correction of CFTR: a small pilot study. Pediatr Diabetes. 2013;14(6):417-421.

53. Porta EA, Stein AA, Patterson P. Ultrastructural changes of the pancreas and liver in cystic fibrosis. Am J Clin Pathol. 1964;42:451-465.

54. Gibson-Corley KN, Meyerholz DK, Engelhardt JF. Pancreatic pathophysiology in cystic fibrosis. J Pathol. 2016;238(2):311-320

55. Melis N, et al. Revisiting CFTR inhibition: a comparative study of CFTRinh -172 and GlyH-101 inhibitors. Br J Pharmacol. 2014;171(15):3716-3727.

56. Kelly M, et al. Cystic fibrosis transmembrane regulator inhibitors CFTR(inh)-172 and GlyH-101 target mitochondrial functions, independently of chloride channel inhibition. J Pharmacol Exp Ther. 2010;333(1):60-69.

57. Meier JJ, et al. Pancreatic diabetes manifests when beta cell area declines by approximately $65 \%$ in humans. Diabetologia. 2012;55(5):1346-1354

58. Donath MY, Böni-Schnetzler M, Ellingsgaard H, Halban PA, Ehses JA. Cytokine production by islets in health and diabetes: cellular origin, regulation and function. Trends Endocrinol Metab. 2010;21(5):261-267.

59. Ali BR. Is cystic fibrosis-related diabetes an apoptotic consequence of ER stress in pancreatic cells? Med Hypotheses. 2009;72(1):55-57.

60. Wilke M, et al. Mouse models of cystic fibrosis: phenotypic analysis and research applications. J Cyst Fibros. 2011;10 Suppl 2:S152-S171.

61. Sun X, et al. Adeno-associated virus-targeted disruption of the CFTR gene in cloned ferrets. J Clin Invest. 2008;118(4):1578-1583

62. Zertal-Zidani S, Busiah K, Edelman A, Polak M, Scharfmann R. Small-molecule inhibitors of the cystic fibrosis transmembrane conductance regulator increase pancreatic endocrine cell development in rat and mouse. Diabetologia. 2013;56(2):330-339.

63. Bogdani M, Blackman SM, Ridaura C, Bellocq JP, Powers AC, Aguilar-Bryan L. Structural abnormalities in islets from very young children with cystic fibrosis may contribute to cystic fibrosis-related diabetes. Sci Rep. 2017;7(1):17231.

64. Li L, Somerset S. Digestive system dysfunction in cystic fibrosis: challenges for nutrition therapy. Dig Liver Dis. 2014;46(10):865-874.

65. Unger RH, Eisentraut AM, Madison LL. The effects of total starvation upon the levels of circulating glucagon and insulin in man. J Clin Invest. 1963;42:1031-1039.

66. Rocha DM, Santeusanio F, Faloona GR, Unger RH. Abnormal pancreatic alpha-cell function in bacterial infections. $N E n g l J$ Med. 1973;288(14):700-703.

67. Tamarina NA, Roe MW, Philipson L. Characterization of mice expressing Ins1 gene promoter driven CreERT recombinase for conditional gene deletion in pancreatic $\beta$-cells. Islets. 2014;6(1):e27685.

68. Reinert RB, et al. Tamoxifen-induced Cre-loxP recombination is prolonged in pancreatic islets of adult mice. PLoS One. 2012;7(3):e33529.

69. Hingorani SR, et al. Preinvasive and invasive ductal pancreatic cancer and its early detection in the mouse. Cancer Cell. 2003;4(6):437-450.

70. Brissova M, et al. Intraislet endothelial cells contribute to revascularization of transplanted pancreatic islets. Diabetes. 2004;53(5):1318-1325

71. Kayton NS, et al. Human islet preparations distributed for research exhibit a variety of insulin-secretory profiles. Am J Physiol Endocrinol Metab. 2015;308(7):E592-E602.

72. Dadi PK, Vierra NC, Jacobson DA. Pancreatic $\beta$-cell-specific ablation of TASK-1 channels augments glucose-stimulated calcium entry and insulin secretion, improving glucose tolerance. Endocrinology. 2014;155(10):3757-3768.

73. Balamurugan AN, Chang Y, Fung JJ, Trucco M, Bottino R. Flexible management of enzymatic digestion improves human islet isolation outcome from sub-optimal donor pancreata. Am J Transplant. 2003;3(9):1135-1142.

74. Ricordi C. Methods in Cell Transplantation. Austin, TX, USA: RG Landes; 1995.

75. Bottino R, Balamurugan AN, Bertera S, Pietropaolo M, Trucco M, Piganelli JD. Preservation of human islet cell functional mass by anti-oxidative action of a novel SOD mimic compound. Diabetes. 2002;51(8):2561-2567.

76. Brissova M, et al. $\beta$ Cell function and gene expression are compromised in type 1 diabetes. Cell Rep. 2018;22(10):2667-2676

77. Hajmrle C, et al. Interleukin-1 signaling contributes to acute islet compensation. JCI Insight. 2016;1(4):e86055

78. Sosnay PR, et al. Defining the disease liability of variants in the cystic fibrosis transmembrane conductance regulator gene. Nat Genet. 2013;45(10):1160-1167.

79. Brissova $\mathrm{M}$ et al. Islet microenvironment, modulated by vascular endothelial growth factor-A signaling, promotes $\beta$ cell regeneration. Cell Metab. 2014;19(3):498-511.

80. Malone JH, Oliver B. Microarrays, deep sequencing and the true measure of the transcriptome. BMC Biol. 2011;9:34. 
81. Mortazavi A, Williams BA, McCue K, Schaeffer L, Wold B. Mapping and quantifying mammalian transcriptomes by RNASeq. Nat Methods. 2008;5(7):621-628.

82. Trapnell C, Pachter L, Salzberg SL. TopHat: discovering splice junctions with RNA-Seq. Bioinformatics. 2009;25(9):1105-1111

83. Dillies MA, et al. A comprehensive evaluation of normalization methods for Illumina high-throughput RNA sequencing data analysis. Brief Bioinformatics. 2013;14(6):671-683.

84. Robinson MD, Oshlack A. A scaling normalization method for differential expression analysis of RNA-seq data. Genome Biol. 2010;11(3):R25.

85. Benjamini Y, Hochberg Y. Controlling the false discovery rate: a practical and powerful approach to multiple testing. $J R$ Stat Soc Series B Stat Methodol. 1995;57(1):289-300.

86. Cai Q, et al. Enhanced expression of VEGF-A in $\beta$ cells increases endothelial cell number but impairs islet morphogenesis and $\beta$ cell proliferation. Dev Biol. 2012;367(1):40-54. 